This item was submitted to Loughborough's Research Repository by the author.

Items in Figshare are protected by copyright, with all rights reserved, unless otherwise indicated.

\title{
Ambiguity and optimal portfolio choice with Value-at-Risk constraint
}

PLEASE CITE THE PUBLISHED VERSION

https://doi.org/10.1016/j.frl.2016.04.013

PUBLISHER

(C) Elsevier

VERSION

AM (Accepted Manuscript)

\section{PUBLISHER STATEMENT}

This work is made available according to the conditions of the Creative Commons Attribution-NonCommercialNoDerivatives 4.0 International (CC BY-NC-ND 4.0) licence. Full details of this licence are available at: https://creativecommons.org/licenses/by-nc-nd/4.0/

\section{LICENCE}

CC BY-NC-ND 4.0

\section{REPOSITORY RECORD}

Jang, Bong-Gyu, and Seyoung Park. 2019. "Ambiguity and Optimal Portfolio Choice with Value-at-risk Constraint". figshare. https://hdl.handle.net/2134/27509. 


\title{
Ambiguity and Optimal Portfolio Choice with Value-at-Risk Constraint
}

\author{
Bong-Gyu Jang ${ }^{\dagger}$ and Seyoung Park*
}

\begin{abstract}
Integrating a Value-at-Risk constraint on a fund manager's wealth and ambiguity, we present a model of optimal portfolio choice for a fund manager who allocates her wealth between risky and riskless assets. When a fund manager controls asset composition, her reactions differ with respect to an increase in only risk aversion and only ambiguity aversion. When the sum of coefficients of risk aversion and ambiguity aversion is fixed, the effect of risk aversion on risky investment dominates the effect of ambiguity aversion in that stock holdings are dramatically smaller in the absence of ambiguity aversion than in its presence.
\end{abstract}

keywords: ambiguity aversion, risk aversion, Value-at-Risk (VaR), optimal portfolio, wealth management

$\dagger$ Department of Industrial and Management Engineering, POSTECH, Korea. Tel: +82-54-279-2372, Fax: +82-54-279-2870, E-mail: bonggyujang@postech.ac.kr

* Corresponding author, The Credit Finance Research Institute, The Credit Finance Association of Korea, 12th Fl., Hanway Bldg., 43 Da-donggil, Jung-gu, Seoul, 100-180, Korea, Tel: +82-2-2011-0677, Fax: +82-22011-0701(2), E-mail: seyoungpark86@gmail.com 


\section{Introduction}

Models of dynamic portfolio choice between risky and riskless assets have helped us to understand the testable empirical predictions between asset pricing and consequent portfolio demand, and have been building blocks for testable general equilibrium models. Since the seminal paper of Merton (1969, 1971), a plethora of studies have investigated the optimal asset composition in a dynamic environment, however, their results have failed to make their close relatives attractive prospects for use in practice. ${ }^{1}$

Along with this line, we present a model of optimal portfolio choice that integrates two main motives that have been identified as quantitatively so important in asset pricing, portfolio choice, and recently corporate finance. First, a portfolio constraint is driven by the presence of a Value-at-Risk (VaR) constraint. ${ }^{2}$ Second, ambiguity (or model uncertainty) about equity returns is taken into account when studying optimal portfolio choice. The combination of portfolio constraints and ambiguity can be incrementally attributed exclusively to the financial literature on dynamic portfolio decisions. We hope that some results of this paper will lend themselves to the study of implications for risk management and portfolio choice in practice.

The bulk of literature on dynamic portfolio choice incorporates some of these motives. Models of portfolio choice have been extended to include portfolio constraints that preclude wealth from falling below some prespecified level (Grossman and Vila, 1989; Basak, 1995, Grossman and Zhou, 1996). ${ }^{3}$ In addition, Basak and Shapiro (2001) yield testable predictions

\footnotetext{
${ }^{1}$ For example, notwithstanding a very important empirical observation of moderate equity holdings for investors, the counterfactual results that produced a significant amount of portfolio share have been obtained from the existing literature. Further, in the population as a whole, stock market participation rates have been very low, nevertheless it was optimal for an investor to invest in the stock market (Merton, 1969, 1971). According to Gomes and Michaelides (2005), portfolio share was significantly lower than $100 \%$ and the stock market participation rate in the U.S. population was about $50 \%$.

${ }^{2} \mathrm{VaR}$ is the lowest tail percentile for losses from the distribution of profit and loss. VaR-based risk management has been a popular standard choice by industry regulations (Jorion, 2006). Fund managers and financial institutions use VaR as the relevant risk measure (Hull, 2005). Whether VaR is an appropriate risk measure is still debatable (Basak and Shapiro, 2001; Berkowitz and O'brien, 2002).

${ }^{3} \mathrm{~A}$ number of researchers have showed that portfolio adjustments are significantly affected by various portfolio constraints. For the details, see Cvitanić and Karatzas (1992), Cuoco (1997), and Cuoco and Liu (2000).
} 
about optimal behavior consistent with Value-at-Risk-based risk management. More recently, different from existing literature, Dai et al. (2011) explore the joint impact of position limits of investors and transaction costs incurred when buying and selling stocks.

Understanding the implications of investors' concern about model uncertainty has been so important in finance and hence the effects of uncertainty have also been widely studied through a concept of ambiguity aversion. ${ }^{4}$ Since the seminal paper of Hansen and Sargent (1995), Hansen and Sargent (2001) and Hansen et al. (2006) extend the model of Gilboa and Schmeidler (1989), who axiomatize max-min utility, to a continuous-time robust consumption and portfolio choice model. Epstein and Schneider (2003) derive a recursive model for utility building on an intertemporal model of multiple-priors utility. Garlappi et al. (2007) formulate an ambiguity-averse fund manager's portfolio selection problem within the standard meanvariance portfolio optimization. Anderson et al. (2009) measure the uncertainty as the degree of disagreement of professional forecasters concerning the returns. They derive an uncertaintyreturn trade-off and show that uncertainty can be a more important determinant of equity returns than is risk, which is regarded as volatility in the standard asset pricing.

The study of robustness in optimal portfolio choice is economically significant, but the robustness itself contributes to resolution of various financial puzzles. Uppal and Wang (2003) show that ambiguity leads to a portfolio that substantially underdiversified relative to the standard mean-variance portfolio. Maenhout (2004) provides an alternative explanation for the equity premium puzzle by incorporating homothetic robustness. Liu et al. (2005) in-

\footnotetext{
${ }^{4}$ Importantly, ambiguity and risk must be distinguished from the point of view of probabilized and nonprobabilized events, respectively. Ambiguity refers to an attitude of preference for known risks over unknown risks in decision theory. If a decision maker knows an appropriate probability distribution to guide choice, then ambiguity is a known risk. However, when a decision maker is concerned about an unknown probability distribution, we classify ambiguity as an unknown risk. This type ambiguity has been widely explored by economists (Ellsberg, 1961; Kahneman and Tversky, 1979; Tversky and Kahneman, 1992). On the other hand, Knight (1921) and Keynes (1936) show that decision makers are ambiguity averse, i.e., they have Knightian uncertainty. Note that model uncertainty is equivalent to Knightian uncertainty when decision makers do not know an exact probability distribution. This is why we sometimes consider the interchangeable use of ambiguity and model uncertainty. However, model uncertainty is to some extent different to Knightian uncertainty and this difference should be taken into account when studying ambiguity (or model uncertainty) (Guidolin and Rinaldi, 2013). In this paper, ambiguity (or model uncertainty) is considered as a particular type of model misspecification following Maenhout (2004), i,e., uncertainty about return processes.
} 
vestigate the relationship between asset pricing and imprecise knowledge about rare events, and assert that the option smirk can be explained by ambiguity aversion against rare events. Recently, Ju and Miao (2012) obtain various asset pricing implications by developing a generalized recursive smooth ambiguity model: the procyclical pattern of price-dividend ratios, the countercyclical pattern of equity premia and equity volatility, the leverage effect, and the mean reversion of excess returns.

Integrating a VaR constraint on a fund manager's terminal wealth and ambiguity (or model uncertainty), we present a model of optimal portfolio choice for a fund manager who has to allocate her wealth between risky and riskless assets. To examine the effects of varying coefficients of risk and ambiguity aversions in the simplest possible environment, we consider a financial market with a constant investment opportunity set in a partial equilibrium. We try to devote our attention on investigating how optimal asset composition of a fund manager is affected by the effects of risk and ambiguity aversions, under a VaR constraint on her final wealth. We believe our paper is the first to integrate ambiguity into the portfolio choice while taking into account a realistic portfolio constraint such as the VaR constraint which is a standard choice by industry regulations.

Our end state is to complement two important articles by solving a fund manager's problem explicitly and by obtaining results numerically for the more general case of optimal portfolio choice. Basak and Shapiro (2001) study an optimal portfolio choice with a VaR constraint and conclude that the VaR constraint often leads to fund managers' aggressive stock investment. Maenhout (2004) takes ambiguity about equity returns into account when studying optimal portfolio decisions and asserts that the effects of ambiguity significantly reduce the demand for equities. We show that the aggressive investment due to the consideration of the VaR constraint is true in the absence of the effects of ambiguity. However, in the presence of ambiguity, the effect of the VaR constraint is mitigated.

One can argue that as in Maenhout (2004), ambiguity aversion raises the level of risk aversion by the amount of ambiguity aversion and hence that the effect of ambiguity aversion on a fund manager's asset composition is trivial, even under a VaR constraint on her terminal wealth. However, when a fund manager controls asset composition, her reactions differ with respect to an increase in only risk aversion and only ambiguity aversion. When the sum of coefficients of risk aversion and ambiguity aversion is fixed, the effect of risk aversion on risky 
investment dominates the effect of ambiguity aversion in the sense that stock holdings are dramatically smaller in the absence of ambiguity aversion than in its presence. Accordingly, dynamic portfolio decision is more dependent on the fund manager's risk aversion rather than on the level of ambiguity aversion.

This paper is organized as follows. In Section 2, we describe financial markets and clarify a concept of ambiguity, and introduce a portfolio choice with the VaR constraint. In Section 3 , we provide analytical results for a fund manager's optimal asset composition-and hence wealth-by integrating the VaR constraint on her final wealth and ambiguity. In Section 4, we show numerical implications for ambiguity and optimal asset composition with the VaR constraint with reasonably calibrated market parameters. In Section 5, we check robustness against an expected shortfall constraint. In Section 6, we conclude the paper.

\section{$2 \quad$ The Model}

\subsection{Financial Markets}

A fund manager can trade two assets in a financial market: a risk-free asset (e.g., a bond) and a risky asset (e.g., a stock). The bond price grows at a continuously compounded, constant rate $r>0$. The stock price $S(t)$ is given by a geometric Brownian motion: ${ }^{5}$

$$
d S(t)=\mu S(t) d t+\sigma S(t) d B(t)
$$

where $\mu>r$ is the expected rate of the stock return, $\sigma>0$ is the volatility of the return on the stock, and $B(t)$ is a standard Brownian motion defined on an appropriate probability space. Here, $\mu$ and $\sigma$ are same with the mean and standard deviation of the return on the stock, respectively, and summarize the investment opportunity provided by the stock, i.e., they represent the expected return and risk in the financial market. We assume that $r, \mu, \sigma$ are constant, i.e., that investment opportunity is constant. ${ }^{6}$

We assume that the utility of a fund manager depends only on the market value of her portfolio at a finite horizon. Although much of our analysis might be applicable to the problem

\footnotetext{
${ }^{5}$ The assumption of a geometric Brownian motion for the stock price process is standard in the financial literature on investment (Merton, 1969, 1971).

${ }^{6}$ For treatment of optimal portfolio choice in the presence of a stochastic investment opportunity, see Chanko and Viceira (2005) and Liu (2007).
} 
with intermediate consumption, we devote our attention to the case where the fund manager wishes to maximize her utility of wealth on a deterministic time. In the literature studying mutual fund industry, the problem of maximizing terminal utility of wealth is commonly considered and consistent with a linear fee structure of mutual fund companies (Dai et al., 2011). Further, our problem is appropriate for a fund manager who is evaluated on her fund performance in the time horizon of a year or 6 months (Gompers, 1994; Marston and Craven, 1998; Edmans, 2009).

The wealth process $W(t)$ of the fund manager with an initial wealth $W(0)=w>0$ is given by

$$
d W(t)=\{r+\pi(t)(\mu-r)\} W(t) d t+\pi(t) \sigma W(t) d B(t),
$$

where $\pi(t)$ is the fraction of wealth invested in the stock at time $t$. The fund manager accumulates wealth at the rates equal to $\{r+\pi(t)(\mu-r)\}$. Note that $(\mu-r)$ represents the positive risk premium obtained from risk taking. Since she invests in the stock market and hence is exposed to stock market risk, which is captured by random fluctuations of wealth following the term involving the Brownian motion $B$. Observe that consumption is omitted from the wealth process. However, for pension asset managers, consumption can be modeled as lump sum payments or as a continuous rate. More realistic case for insurance companies is to model consumption as lump sum payments. The sum over all payouts to all contract holders is the total cash flow at a specific time point. For consideration of intermediate lump sum consumption at discrete time points, see Kraft and Steffensen (2013).

We consider a VaR constraint in a fund manager's optimal portfolio choice. Following Basak and Shapiro (2001), we introduce the VaR constraint:

$$
P\{W(T) \geq \underline{W}\} \geq 1-\alpha,
$$

which means that the fund manager will lose more than $W(T)-\underline{W}$ with probability $0 \leq \alpha \leq 1$. The VaR constraint considered in this paper reduces to the case of portfolio insurance, which always constrains the terminal wealth to be above the level $\underline{W}$ when $\alpha=0$ (Grossman and Vila, 1989; Basak, 1995; Grossman and Zhou, 1996). The case of $0<\alpha<1$ allows the terminal wealth to be below $\underline{W}$ with a probability $\alpha$. The VaR constraint is never binding when $\alpha=1$. 


\subsection{A Portfolio Choice with Ambiguity}

We consider a fund manager who would like to find the maximal score of her constant relative risk aversion (CRRA) utility preference for terminal wealth at time $T \in(0, \infty)$. To incorporate ambiguity aversion (or model uncertainty) of the expected rate of the stock return, we adopt the robust preference structure of Anderson et al. (2003). We consider an optimal portfolio choice in the absence of the VaR constraint to improve understanding of ambiguity aversion (Maenhout, 2004). The manager maximizes her CRRA utility preference for final wealth at time $T$ under a worst-case scenario for $h(t)$ :

$$
V(t, w)=\max _{\pi} \min _{h} E_{t}^{h}\left[\int_{t}^{T} \frac{\{\sigma \pi(s) W(s) h(s)\}^{2}}{2 \Psi(s, w)} d s+\frac{W(T)^{1-\gamma}}{1-\gamma}\right]
$$

where $E_{t}^{h}$ is the expectation taken at time $t$ under an alternative measure $\mathcal{Q}^{h}$ which is equivalent to a reference measure $\mathcal{P}$ and $\Psi(s, w)$ measures the strength of the ambiguity aversion (or the preference for robustness). We consider the Radon-Nikodym derivative of an alternative measure $\mathcal{Q}^{h}$ with respect to the reference measure $\mathcal{P}$ :

$$
\exp \left\{\int_{0}^{T} \sigma \pi(t) W(t) h(t) d B(t)-\frac{1}{2} \int_{0}^{T}(\sigma \pi(t) W(t) h(t))^{2} d t\right\}
$$

so that $d B^{h}(t) \equiv d B(t)-\sigma \pi(t) W(t) h(t) d t$ is a standard Brownian motion under $\mathcal{Q}^{h}$ by the Girsanov Theorem. As a result, the wealth process of the fund manager can be restated as the following:

$$
d W(t)=\left[r+\pi(t)(\mu-r)+\sigma^{2} \pi(t)^{2} W(t) h(t)\right] W(t) d t+\sigma \pi(t) W(t) d B^{h}(t)
$$

where $\sigma^{2} \pi(t)^{2} W(t) h(t)$ can be regarded as the perturbed amount of the expected rate of return to the total wealth where the fund manager does not fully trust the reference measure $\mathcal{P} .^{7}$ As the manager is more concerned about the model uncertainty (the larger $h(t)$ ), the more substantial perturbations are considered in her wealth management.

In this case, we obtain the following Hamilton-Jacobi-Bellman (HJB) equation:

$$
0=\max _{\pi} \inf _{h}\left[V_{t}+\{r+\pi(\mu-r)\} w V_{w}+\frac{1}{2} \pi^{2} \sigma^{2} w^{2} V_{w w}+\sigma^{2} \pi^{2} w^{2} h V_{w}+\frac{1}{2 \Psi(t, w)} \sigma^{2} \pi^{2} w^{2} h^{2}\right] .
$$

\footnotetext{
${ }^{7}$ The distorted drift of the wealth process can be interpreted as robustness against ambiguity (or model uncertainty) in terms of a change of measure from the reference measure to the alternative measure (Cont, 2006).
} 
The drift adjustment $h$ is chosen to minimize the three terms of the HJB equation (3). The first term $V_{t}+\{r+\pi(\mu-r)\} w V_{w}+\frac{1}{2} \pi^{2} \sigma^{2} w^{2} V_{w w}$ comes from the classical Merton's (1969, 1971) Bellman equation. The second one, $\sigma^{2} \pi^{2} w^{2} h V_{w}$, stems from the drift adjustment term in the wealth process (2). Finally, the $\frac{1}{2 \Psi(t, w)} \sigma^{2} \pi^{2} w^{2} h^{2}$ term represents an entropy penalty (Anderson et al. 2003) in which $\Psi(t, w) \geq 0$ measures the strength of the ambiguity aversion (or the preference for robustness). Actually, in this paper the ambiguity aversion is replaced by the homothetic robustness as in Maenhout (2004). We introduce a nonnegative constant $\theta$ as

$$
\Psi(t, w)=\frac{\theta}{(1-\gamma) V(t, w)} .
$$

Hereafter, we let $\theta \geq 0$ denote the ambiguity aversion (or the homothetic robustness). As an extreme case when $\theta=0$ the fund manager cannot choose any nonzero values of $h$ and in turn, she is not ambiguity-averse. When $\theta=\infty$, the manager should choose the largest value of $h$, so that it results in minimizing the drift of wealth process (2) as much as possible; in this case, the manager is extremely ambiguity-averse.

Now we explore the effects of ambiguity aversion on the optimal asset composition for a fund manager who chooses to allocate her wealth between risky and riskless assets, under a VaR constraint on her terminal wealth. This is considered as the following optimization problem with a constraint:

$$
V(t, w)=\max _{\pi} \min _{h} E_{t}^{h}\left[\int_{t}^{T} \frac{\{\sigma \pi(s) W(s) h(s)\}^{2}}{2 \Psi(s, w)} d s+\frac{W(T)^{1-\gamma}}{1-\gamma}\right]
$$

subject to

$$
P\{W(T) \geq \underline{W}\} \geq 1-\alpha .
$$

\section{Analytical Results}

We use the dynamic programming approach to solve the fund manager's problem with the VaR constraint and ambiguity aversion (Kraft and Steffensen, 2013). We specify the main idea of Kraft and Steffensen (2013) and then apply it to our optimal portfolio choice problem. First, we consider only ambiguity aversion for the optimal asset composition; then our problem reduces to Maenhout (2004) without intertemporal consumption choice in a finite horizon set-up. 
We introduce benchmark portfolio $X$ as follows: $X$ consists of two assets; a risk-free investment and a risky investment. By substituting optimal risky investment $\pi^{*}$ and endogenous drift adjustment $h^{*}$ obtained from the HJB (3) into the wealth process (2), we obtain the dynamics for benchmark portfolio $X:^{8}$

$$
d X(t)=\left(r+\frac{\kappa \kappa_{\theta}}{\gamma+\theta}\right) X(t) d t+\frac{\kappa}{\gamma+\theta} X(t) d B(t), \quad X(0)=x>0,
$$

where $\kappa=(\mu-r) / \sigma$ denotes the Sharpe ratio and $\kappa_{\theta}=\kappa-\frac{\kappa \theta}{\gamma+\theta}$ is the Sharpe ratio adjusted with ambiguity aversion $\theta$. In the absence of the VaR constraint, a fund manager with ambiguity aversion by investing in the stock market earns instantaneous profit at the expected rate of $r+\kappa \kappa_{\theta} /(\gamma+\theta)$, which is higher than the risk-free interest rate $r$. This is the compensation for bearing market risk from stock investment and this compensation decreases with risk aversion $\gamma$ and ambiguity aversion $\theta$. In fact, the profit decreases with the so-called effective risk aversion $\gamma+\theta$. However, the effect of ambiguity aversion on benchmark portfolio $X$ is not trivial, because the Sharpe ratio $\kappa_{\theta}$ adjusted with $\theta$ contributes to the expected rate of benchmark portfolio return.

Additionally, the return for $X$ is significantly affected by ambiguity aversion, due to the volatility term $\kappa /(\gamma+\theta)$. As in Maenhout (2004), risk aversion $\gamma$ is increased by $\theta$ to $\gamma+\theta$. Then the volatility of $X$ decreases with respect to an increase in $\gamma+\theta$ and subsequently, the volatility is expected to be lower in the presence of ambiguity aversion than in its absence.

For pension asset managers who have inflows and outflows by contract holders, consumption can be implemented as either a consumption rate or lump sum payments. Let's consider intermediate consumption choice in the managers' objective function. This is applicable to the case where stakeholders of an insurance company obtain utility of the cash-flows from the payments by policy holders. Then the drift term in the bechmark portfolio process is reduced by the amount of consumption. ${ }^{9}$ From a practical point of view, the pension fund managers have inflows and outflows at a regular basis. In this case, their benchmark portfolio process has additional minus terms involving lump sum payments. Regardless of whether or not consumption is modeled as either a consumption rate or lump sum payments, consumption

\footnotetext{
${ }^{8}$ For the details of derivations of the dynamics for $X$, see Appendix 7.1.

${ }^{9}$ According to Maenhout (2004), the intertemporal consumption rule with ambiguity aversion in a finite horizon is the standard Merton's solution except for that the level of risk aversion is raised by the amount of ambiguity aversion.
} 
affects the benchmark portfolio return negatively. Accordingly, a fund manager controls asset composition conservatively in the presence of consumption, ceteris paribus. For technical simplicity, we restrict our attention to the case where there is no utility from consumption and no constraint on consumption. ${ }^{10}$

The benchmark portfolio takes a major role in a fund manager's optimal portfolio choice with the VaR constraint. In the presence of the VaR constraint, the ambiguity-averse fund manager formulates her portfolio strategy based on the benchmark portfolio. In the next section, we will show that the portfolio consists of positions in options contingent on the benchmark portfolio. Importantly, the relationship between the benchmark portfolio and the strike prices at terminal time is a key determinant of terminal wealth management.

We state a theorem concerning wealth process $W$ and optimal investment $\pi^{*}$ in the stock for an ambiguity-averse fund manager with the VaR constraint. We obtain analytical results characterized by benchmark portfolio $X$. To begin with, we introduce the classical Black and Scholes (1973) model. We denote the call option value by

$$
\operatorname{Call}(t, x, r, \sigma, K)=N\left(d_{1}(t, x, r, \sigma, K)\right) x-N\left(d_{2}(t, x, r, \sigma, K)\right) K e^{-r(T-t)},
$$

where

$d_{1}(t, x, r, \sigma, K)=\frac{1}{\sigma \sqrt{T-t}}\left[\ln \left(\frac{x}{K}\right)+\left(r+\frac{\sigma^{2}}{2}\right)(T-t)\right], \quad d_{2}(t, x, r, \sigma, K)=d_{1}(t, x, r, \sigma, K)-\sigma \sqrt{T-t}$, and $N(\cdot)$ is the cumulative distribution function of the standard normal distribution. Here, $x$ is the price of the underlying asset at time $t, r$ is the risk-free interest rate, $\sigma$ is the volatility of returns of the underlying asset, and $K$ is the strike price. The put option value is given by put-call parity as

$$
\operatorname{Put}(t, x, r, \sigma, K)=N\left(-d_{2}(t, x, r, \sigma, K)\right) K e^{-r(T-t)}-N\left(-d_{1}(t, x, r, \sigma, K)\right) x .
$$

Theorem 3.1 An ambiguity-averse fund manager makes robust decisions for portfolio management. Specifically, the manager's wealth process $W(t)$ follows

$$
\begin{aligned}
W(t)=X(t)+P u t\left(t, x, r, \frac{\kappa}{\gamma+\theta}, \underline{W}\right)- & P u t\left(t, x, r, \frac{\kappa}{\gamma+\theta}, k_{\alpha}\right) \\
& -\left(\underline{W}-k_{\alpha}\right) e^{-r(T-t)} P^{Q}\left\{X(T)<k_{\alpha}\right\},
\end{aligned}
$$

\footnotetext{
${ }^{10}$ Kraft and Steffensen (2013) derive results for constrained portfolio problems that have constraints on consumption and wealth in the absence of ambiguity aversion. We leave the fund management problem with ambiguity aversion and consumption as an extension of the paper.
} 
where $\theta$ is ambiguity aversion and $k_{\alpha}$ is a constant to be determined by the VaR constraint, and $Q$ is a risk-neutral measure. Here, benchmark portfolio $X$ follows

$$
d X(t)=r X(t) d t+\frac{\kappa}{\gamma+\theta} X(t) d \tilde{B}(t), \quad X(0)=x>0,
$$

under the $Q$ measure. ${ }^{11}$ The optimal investment $\pi^{*}(t)$ in the stock follows

$$
\pi^{*}(t)=\frac{\mu-r}{\sigma^{2}} \frac{W_{x}(t)}{W(t)} \frac{1}{\left[\frac{\gamma}{x}+\frac{\theta}{(1-\gamma) V(t, w)} V_{x}(t, w)\right]},
$$

where $f_{x}$ denotes the derivative of $f$ with respect to $x$.

\section{Proof. See Appendix 7.2. Q.E.D.}

The wealth process (4) for an ambiguity-averse fund manager with the VaR constraint in Theorem 3.1 is a combination of portfolio insurance and a short position in binary options. Equivalently, the wealth consists of a portfolio strategy without the VaR constraint and an appropriate position in corridor options. Importantly, ambiguity aversion $\theta$ directly affects option prices in the wealth process (4) by the volatility term $\kappa /(\gamma+\theta)$ of benchmark portfolio $X$.

The ambiguity-averse fund manager invests in the benchmark portfolio; this is the first term $X$ of the right hand side in (4). As previously noted, the manager makes robust decision against her ambiguity aversion, as a result, the ambiguity aversion has an important influence on the expected rate of return and volatility for the benchmark portfolio. The decision whether or not to invest in the benchmark portfolio is robust against the ambiguity aversion, but cannot constrain the manager's wealth to be above the floor $\underline{W}$ and hence does not satisfy the VaR constraint.

To reflect the VaR constraint in wealth management, the manager can take a position in a put option. Purchasing a put option with strike price $\underline{W}$ is the simplest strategy. This is the so-called portfolio insurance strategy. In the wealth process (4) the second term of the right hand side reflects such strategy. The difference between our strategy and traditional portfolio insurance strategy is induced by ambiguity aversion of a fund manager. Moreover, our strategy is less expensive than the traditional one because the volatility $\kappa /(\gamma+\theta)$ of the benchmark portfolio decreases with the nonnegative ambiguity aversion $\theta$ and hence results in a lower price of the put option on the less volatile benchmark portfolio.

\footnotetext{
${ }^{11} \tilde{B}(t) \equiv B(t)+\kappa_{\theta} t$ is a standard Brownian motion under the $Q$ measure.
} 
Notwithstanding the perfect strategy that maintains wealth to be above $\underline{W}$ in all states, it still requires expense to purchase the put option. The fund manager knows that the probability that her wealth is significantly lower than $\underline{W}$ is very small in favorable states or economic expansions. Allowing the shortfall of wealth from $\underline{W}$ within some tolerance is effective in reducing costs for wealth management with the VaR constraint. In fact, the shortfall is achieved by a short position in a put option with a lower strike price than $\underline{W}$ (third term of the right hand side in (4)). However, in exchange for allowing the shortfall from $\underline{W}$ the manager is exposed to large losses during unfavorable states or economic downturns. This gives rise to the last term of the right hand side in (4).

Concerning optimal risky investment $\pi^{*}$, Theorem 3.1 yields that ambiguity aversion of a fund manager significantly affects her risky portfolio management. Most importantly, the effects of ambiguity aversion are not monotone with ambiguity aversion, which is contrary to Maenhout (2004) who shows that ambiguity aversion $\theta$ combines with risk aversion $\gamma$ as effective risk aversion $\gamma+\theta$. The ratio between the first derivative of value function and the value function itself is included in the risky investment $\pi^{*}$ with ambiguity aversion $\theta$. As a result, risk aversion $\gamma$ and ambiguity aversion $\theta$ affect the stock holdings separately.

Corollary 3.1 The terminal wealth $W(T)$ follows

$$
W(T)=\left\{\begin{array}{l}
X(T) \text { if } X(T)<k_{\alpha}, \\
\underline{W} \text { if } k_{\alpha} \leq X(T)<\underline{W}, \\
X(T) \text { if } X(T)>\underline{W} .
\end{array}\right.
$$

Proof. The proof of the corollary is straightforward from the proof of Theorem 3.1. For the details, see Appendix 7.2. Q.E.D.

As previously noticed, the fund manager's robust wealth management consists of portfolio insurance and a short position in binary options. Here, we have stressed that benchmark portfolio $X$ is the underlying asset of the options and highly dependent on the manager's ambiguity aversion $\theta$. Corollary 3.1 yields that terminal wealth $W(T)$ resembles option payoffs; the fact that whether or not the price $X$ of benchmark portfolio is under or over the strike prices at terminal time $T$ is a key determinant of $W(T)$. Accordingly, the role of ambiguity aversion in managing wealth is important. Specifically, the manager's wealth is exactly the same as the benchmark portfolio $X$ if the terminal value $X(T)$ is significantly lower than 
strike price $k_{\alpha}$ or higher than strike price $\underline{W}$. If $X$ at $T$ lies between the strike prices, then the terminal wealth $W(T)$ becomes the floor $\underline{W}$. This option-like payoff means that the fund manager protects her wealth to be above the floor $\underline{W}$ if the benchmark portfolio performs well in the market, but exposes her wealth to large losses if the benchmark portfolio is poor.

\section{Numerical Implications}

\subsection{Baseline Parameters}

We set the baseline parameters as follows: $r=3.71 \%$, the annual rate of return from rollingover 1-month T-bills during the time period of $1926-2009,{ }^{12} \mu=11.23 \%$ and $\sigma=19.54 \%$, the return and standard deviation of a portfolio consisting of the world's large stocks during the same time period. ${ }^{13}$ Gompers (1994), Marston and Craven (1998), Edmans (2009) argue that fund managers are myopic because they are evaluated on their fund performance in the time horizon of a year or 6 months; therefore, we set terminal time for a fund manager as $T=1$. We also take the probability of allowing the shortfall from the VaR constraint as $\alpha=1 \%$. Following Basak and Shapiro (2001), we choose the value for the floor of wealth as $\underline{W}=0.9$ and initial value for the underlying asset $X$ as $x=1$.

The remaining parameters to be calibrated are the coefficient of relative risk aversion $\gamma$ and ambiguity aversion $\theta$. For the calibration, we follow Maenhout (2004) who suggests guidance in determining a reasonable value for $\theta$ by using optimal portfolio. Specifically, for low, moderate, and high risk aversion, Maenhout (2004) shows how different values of $\theta$ generate portfolio share and match pessimistic scenarios that contain equity premia in the $3 \%$ range (Cochrane, 1998).

The analytical results for the wealth process and optimal investment in the stock indicate that the wealth is significantly affected by the VaR constraint and accordingly, that the risky investment also varies according to the changes in the wealth. In this sense, not just risk aversion and ambiguity aversion, but the VaR constraint influence how optimal portfolio is determined. Hence, we calibrate the parameters values for $\gamma$ and $\theta$ in the absence of the VaR constraint, thereby removing the effect of the VaR constraint on portfolio share.

\footnotetext{
${ }^{12}$ Source: Bureau of Labor Statistics

${ }^{13}$ pp. 170 of Bodie, Kane, and Marcus (2011).
} 
When we eliminate the terms stemming from the $\mathrm{VaR}$ constraint in the wealth process (4), the optimal investment $\pi^{*}$ in the stock reduces to

$$
\pi^{*}(t)=\frac{\mu-r}{(\gamma+\theta) \sigma^{2}}
$$

which is exactly the same as the portfolio share in Maenhout (2004). We report the sensitivity of risky investment and equity premium to changes in risk aversion $\gamma$ and ambiguity aversion $\theta$ (Table 1). Portfolio share and equity premium heavily depend on the parameter values for $\gamma$ and $\theta$ : an increase in $\gamma$ or $\theta$ (or both) reduces both portfolio share and equity premium.

\section{[Insert Table 1 here.]}

True equity premium is $6 \%$, which is the historical average value (Gomes and Michaelides, 2005; Benzoni et al., 2007; Wachter and Yogo, 2010). In this paper, we choose a conservative equity premium of $3 \%$ to reflect pessimistic scenarios. The $3 \%$ worse case premium is not distinguishable from the $6 \%$ true equity premium when the data of a century-long time series are utilized (Maenhout, 2004). We set $\gamma=2$, which is the standard and moderate risk aversion. Then the reasonably calibrated value for $\theta$ is 3 ; it generates $39.4 \%$ portfolio share and resolves the moderate equity holdings puzzle (or equivalently, the fact that portfolio share is significantly lower than $100 \%$ ).

We summarize the calibration results for parameters in Table 2.

[Insert Table 2 here.]

\subsection{Ambiguity and Optimal Asset Composition with VaR Constraint}

In this section, we investigate how a fund manager's asset composition is affected by the joint consideration of the VaR constraint and the manager's ambiguity aversion. Concerning the wealth process for the fund manager, when we consider the ambiguity aversion, it just seems to increase risk aversion $\gamma$ by $\gamma+\theta$. In this sense, the ambiguity-averse fund manager may behave with not risk aversion $\gamma$ alone, but with effective risk aversion $\gamma+\theta$. The question of whether or not the effect of ambiguity aversion is also monotone with the VaR constraint and just sums with the amount of risk aversion is addressed by numerical analysis. 
Terminal wealth management. We have shown that terminal wealth has an option-like payoff depending on the performance of benchmark portfolio. Terminal wealth management yields a discontinuity at $k_{\alpha}$ (Figure 1); this implies that at maturity a fund manager allows the shortfall of her wealth from the floor $\underline{W}$ with probability $\alpha$. If the benchmark portfolio underperforms in a financial market, or equivalently if $X$ is below $k_{\alpha}$, then wealth of the fund manager is exposed to large losses. In this sense, $k_{\alpha}$ is a tolerance for bearing losses. An increase in $k_{\alpha}$ reduces tolerance for losses.

\section{[Insert Figure 1 here.]}

When a fund manager makes decisions in managing her wealth against ambiguity aversion, the exposed losses are significantly reduced. Actually, the discontinuity in terminal wealth is smaller in the presence of ambiguity aversion than in its absence (Figure 1). The reasonably calibrated value $\theta=3$ for ambiguity aversion induces a larger value for $k_{\alpha}$, so that the fund manager willingly bears smaller losses.

We investigate the effect of ambiguity aversion on a fund manager's wealth management (Table 3). Specifically, when we fix ambiguity aversion $\theta=3$, the tolerance $k_{\alpha}$ for bearing losses increases as risk aversion $\gamma$ increases. Similarly, when $\gamma=5$, the tolerance for losses also increases as $\theta$ increases. This implies that the fund manager tends to have smaller tolerance for bearing losses as the sum $\gamma+\theta$ of coefficients of risk aversion and ambiguity aversion increases.

\section{[Insert Table 3 here.]}

One can argue that as in Maenhout (2004), ambiguity aversion raises the level of risk aversion by the amount of ambiguity aversion and hence that the effect of ambiguity aversion on wealth management is trivial. However, when a fund manager manages her wealth, her reactions differ with respect to an increase in only risk aversion and only ambiguity aversion (Table 3). Importantly, when sum $\gamma+\theta$ is constant, the tolerance $k_{\alpha}$ for losses varies depending upon the combination of $(\gamma, \theta)$. For example, the tolerance $k_{\alpha}=0.8754$ when $(\gamma, \theta)=(2,3)$, and $k_{\alpha}=0.8911$ when $(\gamma, \theta)=(5,0)$. The larger value 0.8911 in the absence of ambiguity aversion than the value 0.8754 in the presence of ambiguity aversion implies that a fund manager manages wealth, depending more on her risk preference for market risk (i.e., risk aversion) than the level of ambiguity against equity returns (i.e., ambiguity aversion). 
Surprisingly, a fund manager does not allow any shortfall of her wealth from the floor $\underline{W}$, once risk aversion (or ambiguity aversion or the sum of coefficients of risk aversion and ambiguity aversion) approaches a threshold level. In this sense, the highly risk-averse or ambiguity-averse fund manager is not affected by the VaR constraint, because in that case she is already sufficiently conservative to maintain her wealth to be above the floor $\underline{W}$. To generate larger values of $k_{\alpha}$ than $\underline{W}, \gamma+\theta$ must exceed about 5 .

\section{[Insert Table 4 here.]}

The tolerance $k_{\alpha}$ for bearing losses varies with a fund manager's investment opportunity (Table 4). The fund manager is willing to bear larger losses, which is captured by a smaller value for $k_{\alpha}$, as the investment opportunity improves, if the expected return on the stock increases, or the volatility of the return decreases. Apparently, improvement in investment opportunity offsets the negative effect of the underperformance of the benchmark portfolio.

Time- $t$ wealth management. We have shown that an ambiguity-averse fund manager with the VaR constraint manages her time- $t$ wealth $W(t)$ through a combination of a portfolio insurance and a short position in binary options (Figure 2). The benchmark portfolio $X(t)$ has an important influence on wealth management; time- $t$ wealth of the fund manager increases as the value of $X$ increases, but shows a concavity when the benchmark portfolio stays in an intermediate region. The concavity of wealth becomes remarkable as time $t$ approaches terminal time $T$; this is because near terminal time the fund manager tries very hard to satisfy the VaR constraint and hence raises her wealth as much as possible. Accordingly, at terminal time she allows a shortfall from the floor $\underline{W}$ with probability $\alpha$, resulting in a large drop in her wealth at $X(t)=k_{\alpha}$.

\section{[Insert Figure 2 here.]}

Importantly, a fund manager's robust decision against uncertainty in stock returns would have a large effect on her time- $t$ wealth management. In the absence of ambiguity aversion, the each inflection point of wealth is nearly the same for four cases of time $t$, whereas it shifts on right side in the presence of ambiguity aversion (Figure 2); this shift implies that the ambiguity-averse fund manager is conservative in managing her wealth in that she increases 
wealth in advance even though the benchmark portfolio performs well, or that the benchmark portfolio $X$ is relatively higher than that in the absence of ambiguity aversion. Additionally, the amount of drop in wealth near the terminal time is significantly smaller in the presence of ambiguity aversion than in its absence.

Optimal risky investment. Merton $(1969,1971)$ derives an investment rule (fraction $\pi(t)$ of wealth invested in a stock)

$$
\pi(t)=\frac{\mu-r}{\gamma \sigma^{2}} .
$$

This means that stock holdings are dependent on the Sharpe ratio, $(\mu-r) / \sigma$, and on the coefficient of an investor's relative risk aversion. Intuitively, as investment opportunity improves, stock investment increases. As risk aversion increases, investment in the stock will decrease. When we consider the VaR constraint in the portfolio choice, Merton's investment rule is no longer valid. The optimal risky investment $\pi^{*}$ for a fund manager is not a constant and varies with the VaR constraint (Figure 3). We will explain the details of risky investment in the absence of ambiguity aversion.

\section{[Insert Figure 3 here.]}

Merton's investment rule holds when wealth is lower than $W_{1}$ or greater than $W_{4}$ (Figure 3 ); i.e., the manager is only affected by the VaR constraint if wealth is between these values. Surprisingly, the fund manager reduces stock holdings as wealth increases from $W_{1}$ to $W_{2}$. Instead, she saves more and is willing to accumulate wealth so that the VaR constraint is satisfied at the terminal time. As she accumulates wealth to $W_{2}$, investing more in the stock is certain to increase her wealth. Thus, for wealth between $W_{2}$ and $W_{3}$ the fund manager shows aggressive stock investment with the expectation that optimally managed wealth by this investment satisfies the $\mathrm{VaR}$ constraint at the terminal time. As wealth approaches $W_{3}$, the fund manager again sharply decreases risky investment because she has accumulated a large amount of wealth. When the fund manager has wealth between $W_{3}$ and $W_{4}$, she increasingly follows Merton's investment rule as wealth approaches $W_{4}$ and follows the rule when wealth exceeds $W_{4}$.

Reasonably calibrated ambiguity aversion $\theta$ significantly reduces stock holdings (Figure 3). In particular, the effect of the VaR constraint that leads to aggressive stock investment is 
mitigated when a fund manager makes a robust decision against uncertainty of stock return for stock investment. In fact, this observation is expected by the results of Maenhout (2004) that portfolio share decreases with respect to an increase in effective risk aversion due to ambiguity aversion. Hence, one may conclude that the effect of ambiguity aversion on optimal risky investment is just the result obtained when we raise the coefficient of relative risk aversion by the level of ambiguity aversion. However, in the Analytical Results section we demonstrated that risk aversion and ambiguity aversion affects risky investment separately.

\section{[Insert Figure 4 here.]}

When wealth is sufficiently small or large optimal risky investment $\pi^{*}$ follows the investment rule proposed by Maenhout (2004). In this case, the effect of ambiguity aversion is trivial in that it increases risk aversion by an amount equal to the level of ambiguity aversion. However, in the presence of the VaR constraint the effects of risk aversion and ambiguity aversion should be discriminated. In Figure 4, we assume that the sum of coefficients of risk aversion and ambiguity aversion is fixed; in this case the effect of risk aversion on risky investment dominates the effect of ambiguity aversion in the sense that stock holdings are significantly smaller in the absence of ambiguity aversion than in its presence for wealth between $W_{2}$ and $W_{3} \cdot{ }^{14}$ Similarly as in terminal wealth management, risky investment is more dependent on the fund manager's risk aversion rather than on the level of ambiguity aversion.

\section{[Insert Figure 5 here.]}

The fund manager's optimal portfolio choice shows a monotone property with investment opportunity (Figure 5). The fund manager is willing to decrease her risky investment as the investment opportunity worsens, if the expected rate of stock return decreases, or the stock volatility increases. This follows the traditional investment rule of Merton $(1969,1971)$; an investor optimally increases her investment in the stock as the Sharpe ratio, $(\mu-r) / \sigma$, increases.

\footnotetext{
${ }^{14}$ We do not indicate points $W_{2}$ and $W_{3}$ in the figure. We have already explained the meanings of these points in Figure 4.
} 


\subsection{VaR-Based Risk Management}

In this section, we quantify the degree to which a fund manager using VaR-based risk management is exposed to large losses in bad states. To quantify expected losses, we introduce a loss amount defined as the ratio between the present value of expected losses and the product of the pre-specified probability $\alpha$ and the initial wealth $w$. The loss amount is the loss measured by the size of the shortfall that the fund manager allows with probability $\alpha$ when benchmark portfolio $X$ is lower than tolerance $k_{\alpha}$. The situation that benchmark portfolio plunges in value represents economic downturns.

Theorem 4.1 We define a loss amount as

$$
L(w ; \gamma, \theta)=E\left[\frac{\xi(T)}{\xi}\left(W^{k_{\alpha}}(T)-W(T)\right) \boldsymbol{1}_{\left\{X(T)<k_{\alpha}\right\}}\right] /(\alpha \times w),
$$

where $W^{k_{\alpha}}(T)$ is wealth level that corresponds to $X(T)=k_{\alpha}$, and $\xi(t)$ is a state price density (or stochastic discount factor) that satisfies

$$
d \xi(t)=-r \xi(t) d t-\kappa_{\theta} d B(t), \quad \xi(0)=\xi>0
$$

Then

$$
\begin{aligned}
L(w ; \gamma, \theta)= & \frac{1}{\xi(\alpha \times w)}\left[N\left(-d_{2}\left(0, x, r, \frac{\kappa}{\gamma+\theta}, k_{\alpha}\right)\right) k_{\alpha} e^{-r T}-N\left(-d_{1}\left(0, x, r, \frac{\kappa}{\gamma+\theta}, k_{\alpha}\right)\right) x\right] \\
& +\left(W^{k_{\alpha}}(T)-k_{\alpha}\right) E\left[\frac{\xi(T)}{\xi} \mathbf{1}_{\left\{X(T) \leq k_{\alpha}\right\}}\right] /(\alpha \times w) .
\end{aligned}
$$

Proof. See Appendix 7.3. Q.E.D.

[Insert Table 5 here.]

The expected loss, $L(\cdot)$, is very sensitive to changes in risk aversion $\gamma$ and ambiguity aversion $\theta$ (Table 5). In the absence of ambiguity aversion, a fund manager would experience substantial losses during economic downturns, because she invests aggressively in the stock to accumulate wealth as soon as possible. For example, for standard and moderate risk aversion $\gamma=2$ the fund manager losses $30.6 \%$ of initial wealth during economic downturns when $\theta=0$. The amount of loss decreases significantly as risk aversion $\gamma$ increases, and is $7.1 \%$ when $(\gamma, \theta)=(5,0)$. The ambiguity-averse fund manager effectively reduces losses during economic downturns. In fact, loss decreases significantly from $30.6 \%$ when $(\gamma, \theta)=(2,0)$ to $4.7 \%$ when $(\gamma, \theta)=(2,3)$ (Table 5 ). Therefore, both market risk and ambiguity (or model 
uncertainty) against equity returns that whose aversions are measured by risk aversion and ambiguity aversion, respectively, should be incorporated in VaR-based risk management.

\section{[Insert Table 6 here.]}

The effect of varying investment opportunity on the expected losses is monotonic (Table 6). Similarly to the treatment of the sensitivity of tolerance $k_{\alpha}$ for bearing losses to changes in investment opportunity (Table 4), larger losses arising from the plunge of the benchmark portfolio would be expected as the investment opportunity improves, if the expected stock return increases, or the stock volatility decreases. Further, the aggressive risky investment behavior when the investment opportunity improves (Figure 5) would give rise to such substantial losses when the benchmark portfolio underperforms in a financial market.

\section{Robustness}

An interesting extension to this paper is to overcome the well-known limitations of the VaR constraint. ${ }^{15}$ To consider a general and coherent risk measure, we can write the VaR constraint in an integral form. In particular, an expected shortfall (ES) constraint imposes the percentile for the first moment of losses. The ES constraint satisfies a sub-additivity property and hence it is a coherent risk measure. Accordingly, the ES constraint can be used as an alternative risk measure. More specifically, we consider the following constraint:

$$
E\left[\xi(T)(\underline{W}-W(T)) \mathbf{1}_{\{W(T) \leq \underline{W}\}}\right] \leq \epsilon
$$

where $\epsilon \geq 0$ is a constant. We know that

$$
E\left[\xi(T)(\underline{W}-W(T)) \mathbf{1}_{\{W(T) \leq \underline{W}\}}\right]=E[\xi(T)(\underline{W}-W(T)) \mid W(T) \leq \underline{W}] P\{W(T) \leq \underline{W}\}
$$

This implies that the ES constraint focuses on not only the shortfall probability of not satisfying the terminal wealth $W(T)$, but also the magnitude of the shortfall given that a loss occurs. Analogously to the consideration of the VaR constraint (1), the formulation of the ES

\footnotetext{
${ }^{15} \mathrm{VaR}$ is not a coherent risk measure and hence it may not be appropriate as a risk measure because it would generate large losses during economic downturns (Basak and Shapiro, 2001). Further, currently it is quickly losing VaR's popularity in favor or risk functionals able to capture tail risk (Basel, 2012).
} 
constraint nets the case of portfolio insurance $(\epsilon=0)$ and the case of the benchmark portfolio $(\epsilon=\infty)$.

As in VaR-based risk management we can quantify the degree to which a fund manager using ES-based risk management is exposed to large losses in bad states.

Theorem 5.1 We define a loss amount as

$$
L^{E S}(w ; \gamma, \theta)=E\left[\frac{\xi(T)}{\xi}(\underline{W}-W(T)) \boldsymbol{1}_{\left\{X(T)<k_{\epsilon}\right\}}\right] / \epsilon .
$$

Then $L(\cdot)$ is computed as

$$
L^{E S}(w ; \gamma, \theta)=\frac{W}{k_{\epsilon} \xi \epsilon}\left[N\left(-d_{2}\left(0, x, r, \frac{\kappa}{\gamma+\theta}, k_{\epsilon}\right)\right) k_{\epsilon} e^{-r T}-N\left(-d_{1}\left(0, x, r, \frac{\kappa}{\gamma+\theta}, k_{\epsilon}\right)\right) x\right],
$$

where $k_{\epsilon}$ is a constant to be determined by the ES constraint.

Proof. See Appendix 7.4.

\section{[Insert Table 7 here.]}

The loss $L^{E S}(\cdot)$ is sensitive to changes in risk aversion $\gamma$ and ambiguity aversion $\theta$ (Table 7). As expected, the amount of loss is lower with the ES constraint than with the VaR constraint. When we fix $\gamma=2$, the reasonably calibrated parameter of ambiguity aversion $\theta=3$ gives rise to $3.4 \%$ loss of initial wealth during economic downturns; the loss $15.2 \%$ in the absence of ambiguity aversion is greatly reduced. Importantly, the expected losses are invariant with the kind of constraints (ES or VaR) when the sum $\gamma+\theta$ is large. For instance, with $(\gamma, \theta)=(5,5)$ we expect $1.9 \%$ loss with the ES constraint and $1.7 \%$ loss with the VaR constraint. Hence, in risk management, not only the appropriate risk measure is determined, but also the differences of effects of risk aversion and ambiguity aversion on optimal asset composition should be accounted for.

\section{[Insert Table 8 here.]}

The sensitivity of the loss $L^{E S}(\cdot)$ to changes in investment opportunity is similar to the case of the VaR constraint. Further, observe that the effects of varying expected rate $\mu$ of stock return and risk-free interest rate $r$ are symmetric because the fund manager's optimal portfolio choice depends on the size of risk premium $\mu-r$. Accordingly, a better investment opportunity (a higher Sharpe ratio $(\mu-r) / \sigma$ ) induces larger losses. 


\section{Conclusion}

We present a model of optimal portfolio choice that integrates two main motives: a portfolio constraint driven by the presence of a Value-at-Risk (VaR) constraint and ambiguity (or model uncertainty) about equity returns. We try to focus on investigating how optimal asset composition of a fund manager is affected by the effects of risk and ambiguity aversions, under a VaR constraint on her final wealth. We hope that some results of this paper will lend themselves to the study of implications for risk management and portfolio choice in practice.

One can argue that as in Maenhout (2004), ambiguity aversion raises the level of risk aversion by the amount of ambiguity aversion and hence that the effect of ambiguity aversion on a fund manager's asset composition is trivial, even under a VaR constraint on her terminal wealth. However, when a fund manager controls asset composition, her reactions differ with respect to changes in the coefficients of risk and ambiguity aversions. When the sum of coefficients of risk and ambiguity aversions is fixed, the effect of risk aversion on risky investment dominates the effect of ambiguity aversion in that portfolio shares are significantly smaller in the absence of ambiguity aversion than in its presence. As a result, dynamic portfolio decision is more dependent on the fund manager's risk aversion rather than on the level of ambiguity aversion.

This paper raises a number of questions that should be addressed in any future research on the topic. First, by far the strongest assumption we have made in our modeling for financial markets, is that the investment opportunity set is constant: risk-free interest rate, expected rate of stock return, and stock volatility are all constant. Thus, we have abstracted away from time variation of the investment opportunity set. Beyond the classic Merton $(1969,1971)$ 's model of dynamic portfolio choice, the next step is to allow for more realistic and complicated dynamics for the investment opportunity set.

Second, an interesting extension of our model is to incorporate any reevaluation of a VaR or discrete reporting a VaR. Indeed, Cuoco and Liu (2006) derive an optimal investment strategy for financial institutions in which they mush report their VaR given some discrete reporting periods. Along with this line, Cuoco et al. (2008) overcome the assumption of static or dynamically inconsistent VaR constraints as existing literature have considered. Further research would examine the optimal asset composition including these realistic portfolio constraints. 
Third, we have ignored the positive equilibrium implications, under the normative focus on the paper. The main question raised by this paper is how optimal asset composition is affected by the effects of ambiguity (or model uncertainty), under a VaR constraint on a fund manager's final wealth. Importantly, a detailed equilibrium analysis would attempt to derive the implications for equity premium and risk-free rate in a Lucas-style equilibrium asset pricing model (Basak and Shapiro, 2001; Maenhout, 2004). However, this is far beyond the scope of the current paper.

We believe these issues to be addressed will demand further academic attention as they take on greater responsibility for explaining the economic relevance of ambiguity to risk management and portfolio choice in practice.

\section{Appendix}

\subsection{The Dynamics for Benchmark Portfolio $X$}

According to the HJB equation (3), the optimality condition for $h$ gives

$$
h^{*}=-\Psi V_{w} .
$$

Substituting $h^{*}$ into the HJB equation yields

$$
0=\max _{\pi}\left[V_{t}+\{r+\pi(\mu-r)\} w V_{w}+\frac{1}{2} \pi^{2} \sigma^{2} w^{2} V_{w w}-\frac{1}{2} \Psi \pi^{2} \sigma^{2} w^{2}\left(V_{w}\right)^{2}\right] .
$$

Optimal risky investment $\pi^{*}$ is given by the necessary optimality condition as

$$
\pi^{*}=-\frac{V_{w}}{w\left(V_{w w}-\Psi\left(V_{w}\right)^{2}\right)} \frac{\kappa}{\sigma} .
$$

Then we get the following highly nonlinear differential equation:

$$
0=V_{t}+r w V_{w}-\frac{1}{2} \kappa^{2} \frac{\left(V_{w}\right)^{2}}{\left(V_{w w}-\Psi\left(V_{w}\right)^{2}\right)}-\frac{1}{2} \Psi \kappa^{2} \frac{\left(V_{w}\right)^{4}}{\left(V_{w w}-\Psi\left(V_{w}\right)^{2}\right)^{2}} .
$$

We introduce a nonnegative constant $\theta$ as Maenhout (2004) did:

$$
\Psi(t, w)=\frac{\theta}{(1-\gamma) V(t, w)}
$$


where $\theta$ is the so-called ambiguity aversion (or homothetic robustness). Then the nonlinear differential equation can be rewritten by

$$
0=V_{t}+r w V_{w}-\frac{1}{2} \kappa^{2} \frac{\left(V_{w}\right)^{2}}{\left(V_{w w}-\frac{\theta}{(1-\gamma) V}\left(V_{w}\right)^{2}\right)}-\frac{1}{2} \kappa^{2} \frac{\theta}{(1-\gamma) V(t, w)} \frac{\left(V_{w}\right)^{4}}{\left(V_{w w}-\frac{\theta}{(1-\gamma) V}\left(V_{w}\right)^{2}\right)}
$$

If we conjecture the solution form of $V$ as

$$
V(t, w)=\iota(t) \frac{w^{1-\gamma}}{1-\gamma},
$$

then $\iota(t), h^{*}$ and $\pi^{*}$ are obtained:

$$
\begin{gathered}
\iota(t)=e^{b(T-t)}, \quad b=(1-\gamma)\left[r+\frac{1}{2} \frac{\gamma}{(\gamma+\theta)^{2}} \kappa^{2}\right], \\
h^{*}=-\frac{\kappa \theta}{\gamma+\theta}, \quad \text { and } \pi^{*}=\frac{\kappa}{\sigma(\gamma+\theta)} .
\end{gathered}
$$

When we substitute $h^{*}$ and $\pi^{*}$ into the wealth process (2), we obtain the dynamics for $X$ as follows

$$
d X(t)=\left(r+\frac{\kappa \kappa_{\theta}}{\gamma+\theta}\right) X(t) d t+\frac{\kappa}{\gamma+\theta} X(t) d B(t), \quad X(0)=x>0 .
$$

\subsection{Proof of Theorem 3.1}

Kraft and Steffensen (2013) verify that the value function $V(t, w)$ is equivalent to the following expectation of a function $g$ taken at time $t$ :

$$
V(t, w)=E_{t}[g(X(T))]
$$

where time- $t$ wealth $W(t)$ and the function $g$ are related as

$$
W(t) \equiv W(t, x)=E_{t}^{Q}\left[e^{-r(T-t)} g(X(T))\right]
$$

where $Q$ is a risk-neutral measure. Under the $Q$ measure, the dynamics for $X$ is given by

$$
d X(t)=r X(t) d t+\frac{\kappa}{\gamma+\theta} X(t) d \tilde{B}(t)
$$

where $\tilde{B}(t) \equiv B(t)+\kappa_{\theta} t$ is a standard Brownian motion under the $Q$ measure. Note that time- $t$ wealth $W(t, x)$ can be regarded as an option price for a contingent claim $g$, where

$$
W_{t}=r W-r x W_{x}-\frac{1}{2}\left(\frac{\kappa}{\gamma+\theta}\right)^{2} x^{2} W_{x x}, \quad W(T, x)=g(x) .
$$


We now introduce a Lagrangian multiplier $\lambda_{\alpha}$ so that the fund manager's optimization problem with the VaR constraint is transformed into an unconstrained problem. More specifically, the value function $V$ follows

$$
V(t, w)=E_{t}[\tilde{u}(g(X(T)))]
$$

where

$$
\tilde{u}(x)=\frac{x^{1-\gamma}}{1-\gamma}-\lambda_{\alpha} \mathbf{1}_{\{x<\underline{W}\}}
$$

and a contingent claim $g$ of $X$ should be appropriately determined by the VaR constraint. We conjecture the solution form $g$ as follows:

$$
g(x)=x+(\underline{W}-x) \mathbf{1}_{\{x<\underline{W}\}}-\left(k_{\alpha}-x\right) \mathbf{1}_{\left\{x<k_{\alpha}\right\}}-\left(\underline{W}-k_{\alpha}\right) \mathbf{1}_{\left\{x<k_{\alpha}\right\}},
$$

where a constant $k_{\alpha}$ is attained by $P\{g(X(T))<\underline{W}\}=\alpha$. This conjecture can be verified by the two steps. In the first step, we assume that the pre-specified confidence level $\alpha=1$. Then the fund manager should buy a put option on her final wealth with the strike price $\underline{W}$. This can be captured by the term

$$
x+(\underline{W}-x) \mathbf{1}_{\{x<\underline{W}\}} .
$$

For the next step, within a specified confidence level $0 \leq \alpha<1$, extreme losses are allowed and hence selling another put option with the lower strike price $k_{\alpha}$ than $\underline{W}$ can be considered in the optimal strategy for the fund manager with the VaR constraint. Accordingly, this results in the following:

$$
x+(\underline{W}-x) \mathbf{1}_{\left\{k_{\alpha}<x<\underline{W}\right\}},
$$

which is equivalent to the conjectured form of $g$.

The relationship (5) gives that

$$
\begin{aligned}
W(t, x)= & E_{t}^{Q}\left[e ^ { - r ( T - t ) } \left\{X(T)+(\underline{W}-X(T)) \mathbf{1}_{\{X(T)<\underline{W}\}}-\left(k_{\alpha}-X(T)\right) \mathbf{1}_{\left\{X(T)<k_{\alpha}\right\}}\right.\right. \\
& \left.\left.\quad-\left(\underline{W}-k_{\alpha}\right) \mathbf{1}_{\left\{X(T)<k_{\alpha}\right\}}\right\}\right] \\
= & x+N\left(-d_{2}\left(t, x, r, \frac{\kappa}{\gamma+\theta}, \underline{W}\right)\right) \underline{W} e^{-r(T-t)}-N\left(-d_{1}\left(t, x, r, \frac{\kappa}{\gamma+\theta}, \underline{W}\right)\right) x \\
& -\left\{N\left(-d_{2}\left(t, x, r, \frac{\kappa}{\gamma+\theta}, k_{\alpha}\right)\right) k_{\alpha} e^{-r(T-t)}-N\left(-d_{1}\left(t, x, r, \frac{\kappa}{\gamma+\theta}, k_{\alpha}\right)\right) x\right\} \\
& -\left(\underline{W}-k_{\alpha}\right) e^{-r(T-t)} P^{Q}\left\{X(T)<k_{\alpha}\right\} \\
= & x+\operatorname{Put}\left(t, x, r, \frac{\kappa}{\gamma+\theta}, \underline{W}\right)-P u t\left(t, x, r, \frac{\kappa}{\gamma+\theta}, k_{\alpha}\right)-\left(\underline{W}-k_{\alpha}\right) e^{-r(T-t)} P^{Q}\left\{X(T)<k_{\alpha}\right\} .
\end{aligned}
$$


Furthermore, the value function $V$ is given by

$$
\begin{aligned}
V(t, x) \equiv & V(t, w ; x)=E_{t}[\tilde{u}(g(X(T)))] \\
= & E_{t}\left[\frac{1}{1-\gamma}\left\{X(T)+(\underline{W}-X(T)) \mathbf{1}_{\{X(T)<\underline{W}\}}-\left(k_{\alpha}-X(T)\right) \mathbf{1}_{\left\{X(T)<k_{\alpha}\right\}}-\left(\underline{W}-k_{\alpha}\right) \mathbf{1}_{\left\{X(T)<k_{\alpha}\right\}}\right\}^{1-\gamma}\right. \\
& \left.\quad-\lambda_{\alpha} \mathbf{1}_{\left\{X(T)<k_{\alpha}\right\}}\right] \\
= & \frac{e^{\tilde{r}(T-t)}}{1-\gamma}\left[x^{1-\gamma}+N\left(-d_{2}\left(t, x^{1-\gamma}, \tilde{r}, \frac{(1-\gamma) \kappa}{\gamma+\theta}, \underline{W}^{1-\gamma}\right)\right) \underline{W}^{1-\gamma} e^{-\tilde{r}(T-t)}\right. \\
& -N\left(-d_{1}\left(t, x^{1-\gamma}, \tilde{r}, \frac{(1-\gamma) \kappa}{\gamma+\theta}, \underline{W^{1-\gamma}}\right)\right) x^{1-\gamma}-\left\{N\left(-d_{2}\left(t, x^{1-\gamma}, \tilde{r}, \frac{(1-\gamma) \kappa}{\gamma+\theta}, k_{\alpha}^{1-\gamma}\right)\right)\right. \\
& \left.\left.\times k_{\alpha}^{1-\gamma} e^{-\tilde{r}(T-t)}-N\left(-d_{1}\left(t, x^{1-\gamma}, \tilde{r}, \frac{(1-\gamma) \kappa}{\gamma+\theta}, k_{\alpha}^{1-\gamma}\right)\right) x^{1-\gamma}\right\}\right] \\
& -\frac{e^{\tilde{r}(T-t)}}{1-\gamma}\left(\underline{W}^{1-\gamma}-k_{\alpha}^{1-\gamma}+(1-\gamma) \lambda_{\alpha}\right) e^{-\tilde{r}(T-t)} P\left\{X(T)<k_{\alpha}\right\} \\
= & \frac{e^{\tilde{r}(T-t)}}{1-\gamma}\left[x^{1-\gamma}+P u t\left(t, x^{1-\gamma}, \tilde{r}, \frac{(1-\gamma) \kappa}{\gamma+\theta}, \underline{W^{1-\gamma}}\right)-P u t\left(t, x^{1-\gamma}, \tilde{r}, \frac{(1-\gamma) \kappa}{\gamma+\theta}, k_{\alpha}^{1-\gamma}\right)\right] \\
& -\frac{e^{\tilde{r}(T-t)}}{1-\gamma}\left(\underline{W}^{1-\gamma}-k_{\alpha}^{1-\gamma}+(1-\gamma) \lambda_{\alpha}\right) e^{-\tilde{r}(T-t)} P\left\{X(T)<k_{\alpha}\right\},
\end{aligned}
$$

where

$$
\tilde{r}=(1-\gamma)\left(r+\frac{1}{2} \frac{\kappa \kappa_{\theta}}{\gamma+\theta}\right) .
$$

One can easily verify the following relationships:

$$
\begin{aligned}
& \frac{\partial}{\partial x} \operatorname{Put}\left(t, x, r, \frac{\kappa}{\gamma+\theta}, \underline{W}\right)=\frac{x^{\gamma}}{1-\gamma} \frac{\partial}{\partial x} \operatorname{Put}\left(t, x^{1-\gamma}, \tilde{r}, \frac{(1-\gamma) \kappa}{\gamma+\theta}, \underline{W}^{1-\gamma}\right), \\
& e^{-\tilde{r}(T-t)} \frac{\partial}{\partial x} P\left\{X(T)<k_{\alpha}\right\}=\left(\frac{x}{k_{\alpha}}\right)^{-\gamma} e^{-r(T-t)} \frac{\partial}{\partial x} P^{Q}\left\{X(T)<k_{\alpha}\right\},
\end{aligned}
$$

leading to the following equation:

$$
V_{x}(t, w ; x)=e^{\tilde{r}(T-t)} x^{-\gamma} W_{x}(t, x)
$$

under the condition that

$$
\lambda_{\alpha}=\left(\underline{W}-k_{\alpha}\right) k_{\alpha}^{-\gamma}-\frac{W^{1-\gamma}}{1-\gamma}+\frac{k_{\alpha}^{1-\gamma}}{1-\gamma} .
$$

According to the above condition, when the constant $k_{\alpha}$ is achieved by $P\{g(X(T))<\underline{W}\}=\alpha$ the Lagrangian multiplier $\lambda_{\alpha}$ is also determined.

Also, a direct computation results in

$$
V_{x x}(t, w ; x)=-\gamma e^{\tilde{r}(T-t)} x^{-\gamma-1} W_{x}(t, x)+e^{\tilde{r}(T-t)} x^{-\gamma} W_{x x}(t, x) .
$$

Then we obtain

$$
-\frac{x V_{x x}}{V_{x}}=-\frac{x W_{x x}}{W_{x}}+\gamma
$$


By the chain rule, we get

$$
V_{x}=V_{w} W_{x} \text { and } V_{x x}=V_{w w}\left(W_{x}\right)^{2}+V_{w} W_{x x} .
$$

Hence,

$$
-\frac{x V_{x x}}{V_{x}}=-\frac{x\left\{V_{w w}\left(W_{x}\right)^{2}+V_{w} W_{x x}\right\}}{V_{w} W_{x}}=-\frac{x V_{w w}}{V_{w}} W_{x}-\frac{x W_{x x}}{W_{x}} .
$$

Using the relation of (6), we obtain

$$
\frac{V_{w w}}{V_{w}}=-\frac{\gamma}{x W_{x}} .
$$

Recall that optimality condition for risky investment is given by

$$
\pi^{*}=-\frac{\kappa}{\sigma} \frac{1}{w\left(\frac{V_{w w}}{V_{w}}-\frac{\theta}{(1-\gamma)} \frac{V_{w}}{V}\right)} .
$$

Utilizing the equations of (6), (7), and (8) concludes the proof of Theorem 3.1.

\subsection{Proof of Theorem 4.1}

One can show that

$$
\begin{aligned}
L(x ; w, \theta)= & E\left[\frac{\xi(T)}{\xi}\left(W^{k_{\alpha}}(T)-g(X(T))\right) \mathbf{1}_{\left\{g(X(T))<k_{\alpha}\right\}}\right] /(\alpha \times w) \\
= & E\left[\frac{\xi(T)}{\xi}\left(W\left(k_{\alpha}\right)-g(X(T))\right) \mathbf{1}_{\left\{X(T)<k_{\alpha}\right\}}\right] /(\alpha \times w) \\
= & E\left[\frac{\xi(T)}{\xi}\left(W\left(k_{\alpha}\right)-X(T)\right) \mathbf{1}_{\left\{X(T)<k_{\alpha}\right\}}\right] /(\alpha \times w) \\
= & E\left[\frac{\xi(T)}{\xi}\left(k_{\alpha}-X(T)\right) \mathbf{1}_{\left\{X(T) \leq k_{\alpha}\right\}}\right] /(\alpha \times w)+E\left[\frac{\xi(T)}{\xi}\left(W\left(k_{\alpha}\right)-k_{\alpha}\right) \mathbf{1}_{\left\{X(T) \leq k_{\alpha}\right\}}\right] /(\alpha \times w) \\
= & \frac{1}{\xi(\alpha \times w)}\left[N\left(-d_{2}\left(0, x, r, \frac{\kappa}{\gamma+\theta}, k_{\alpha}\right)\right) k_{\alpha} e^{-r T}-N\left(-d_{1}\left(0, x, r, \frac{\kappa}{\gamma+\theta}, k_{\alpha}\right)\right) x\right] \\
& +\left(W^{k_{\alpha}}(T)-k_{\alpha}\right) E\left[\frac{\xi(T)}{\xi} \mathbf{1}_{\left\{X(T) \leq k_{\alpha}\right\}}\right] /(\alpha \times w) .
\end{aligned}
$$




\subsection{Proof of Theorem 5.1}

A straightforward calculation yields

$$
\begin{aligned}
L(x ; w, \theta) & =E\left[\frac{\xi(T)}{\xi}(\underline{W}-g(X(T))) \mathbf{1}_{\left\{g(X(T))<k_{\epsilon}\right\}}\right] / \epsilon \\
& =E\left[\frac{\xi(T)}{\xi}(\underline{W}-g(X(T))) \mathbf{1}_{\left\{X(T)<k_{\epsilon}\right\}}\right] / \epsilon \\
& =E\left[\frac{\xi(T)}{\xi}\left(\underline{W}-\frac{\underline{W}}{k_{\epsilon}} X(T)\right) \mathbf{1}_{\left\{X(T)<k_{\epsilon}\right\}}\right] / \epsilon \\
& =\frac{W}{k_{\epsilon} \xi \epsilon} E\left[\xi(T)\left(k_{\epsilon}-X(T)\right) \mathbf{1}_{\left\{X(T)<k_{\epsilon}\right\}}\right] \\
& =\frac{W}{k_{\epsilon} \xi \epsilon}\left[N\left(-d_{2}\left(0, x, r, \frac{\kappa}{\gamma+\theta}, k_{\epsilon}\right)\right) k_{\epsilon} e^{-r T}-N\left(-d_{1}\left(0, x, r, \frac{\kappa}{\gamma+\theta}, k_{\epsilon}\right)\right) x\right] .
\end{aligned}
$$

Acknowledgement. A primitive version of the paper titled "Robust Portfolio Management with VaR Constraint" was presented at the 10th Annual Conference of the Asia-Pacific Association of Derivatives. This research in the paper is supported by the National Research Foundation of Korea Grant funded by the Korean Government (NRF-2013R1A2A2A03068890, NRF-2014S1A3A2036037).

\section{References}

Anderson, E. W., L. P. Hansen, and T. J. Sargent. 2003. A Quartet of Semi-Groups for Model Specification, Robustness, Prices of Risk, and Model Detection. Journal of the European Economic Association. 1 68-123.

Anderson, E. W., E. Ghysels, and J. L. Juergens. 2009. The impact of risk and uncertainty on expected returns. Journal of Financial Economics. 94 233-263.

Basak, S. 1995. A General Equilibrium Model of Portfolio Insurance. Review of Financial Studies. 8 1059-1090.

Basak, S., and A. Shapiro. 2001. Value-at-Risk Based Risk Management: Optimal Policies and Asset Prices. Review of Financial Studies. 14 371-405.

Basel, 2012. The Fundamental Review of the Trading Book. Basel Committee on Banking Supervision. 
Benzoni, L., P. Collin-Dufresne, and R. S. Goldstein. 2007. Portfolio Choice over the LifeCycle when the Stock and Labor Markets Are Cointegrated. Journal of Finance. 62 21232167.

Berkowitz, J., and J. O'brien. 2002. How Accurate Are Value-at-Risk Models at Commercial Banks? Journal of Finance. 57 1093-1111.

Black, F., and M. Scholes. 1973. The Pricing of Options and Corporate Liabilities. Journal of Political Economy. 81 637-654.

Bodie, Z., A. Kane, and A. J. Marcus. 2011. Investments and Portfolio Management. McGrawHill, Ninth Edition.

Chacko, G., and L. M. Viceira. 2005. Dynamic Consumption and Portfolio Choice with Stochastic Volatility in Incomplete Markets. Review of Financial Studies. 18 1369-1402.

Cochrane, J. 1998. Where is the Market Going? Uncertain Facts and Novel Theories. Working Paper.

Cont, R. 2006. Model Uncertainty and Its Impact on the Pricing of Derivatives Instruments. Mathematical Finance. 16 519-547.

Cuoco, D. 1997. Optimal Consumption and Equilibrium Prices with Portfolio Constraints and Stochastic Income. Journal of Economic Theory. 72 33-73.

Cuoco, D., and H. Liu. 2000. A Martingale Characterization of Consumption Choices and Hedging Costs with Margin Requirements. Mathematical Finance. 10 355-385.

Cuoco, D., and H. Liu. 2006. An Analysis of VaR-Based Capital Requirements. Journal of Financial Intermediation. 15 362-394.

Cuoco, D., H. He, and S. Isaenko. 2008. Optimal Dynamic Trading Strategies with Risk Limits. Operations Research. 56 358-368.

Cvitanić, J., and I. Karatzas. 1999. On Dynamic Measures of Risk. Finance and Stochastics. 3 451-482.

Dai, M., H. Jin, and H. Liu. 2011. Illiquidity, Position Limits, and Optimal Investment for Mutual Funds. Journal of Economic Theory. 146 1598-1630. 
Edmans, A. 2009. Blockholder Trading, Market Efficiency, and Managerial Myopia. Journal of Finance. 64 2481-2513.

Ellsberg, D. 1961. Risk, Ambiguity and the Savage Axioms. Quarterly Journal of Economics. $75643-669$.

Epstein, L. G., and M. Scheneider. 2003. Recursive Multiple-Priors. Journal of Economic Theory. 113 1-31.

Garlappi, L., R. Uppal, and T. Wang. 2007. Portfolio Selection with Parameter and Model Uncertainty: a Multi-Prior Approach. Review of Financial Studies. 20 41-81.

Gilboa, I., and D. Schmeidler. 1989. Maxmin Expected Utility with Non-unique Prior. Journal of Mathematical Economics. 18 141-153.

Gomes, F., and A. Michaelides. 2005. Optimal Life-Cycle Asset Allocation: Understanding the Empirical Evidence. Journal of Finance. 60 869-904.

Gompers, P. A. 1994. The Rise and Fall of Venture Capital. Business and Economic History. $231-26$.

Grossman, S. J., and J. Vila. 1989. Portfolio Insurance in Complete Markets: A Note. Journal of Business. 62 473-476.

Grossman, S. J., and Z. Zhou. 1996. Equilibrium Analysis of Portfolio Insurance. Journal of Finance. 51 1379-1403.

Guidolin, M., and F. Rinaldi. 2013. Ambiguity in Asset Pricing and Portfolio Choice: A Review of the Literature. Theory and Decision. $\mathbf{7 4}$ 183-217.

Hansen, L. P., and T. J. Sargent. 1995. Discounted Linear Exponential Quadratic Gaussian Control. IEEE Transactions on Automatic Control. 40 968-971.

Hansen, L. P., and T. J. Sargent. 2001. Robust Control and Model Uncertainty. American Economic Review. 91 60-66.

Hansen, L. P., T. J. Sargent, G. Turmuhambetova, and N. Williams. 2006. Robust Control and Model Misspecification. Journal of Economic Theory. 128 45-90.

Hull, J. C. 2005. Options, Futures, and Other Derivatives. Pearson/Prentice Hall, Sixth 


\section{Edition.}

Jorion, P. 2006. Value at Risk: The New Benchmark for Managing Financial Risk. McGrawHill, Third Edition.

Ju, N., and J. Miao. 2012. Ambiguity, Learning, and Returns. Econometrica. 80 559-591.

Kahneman, D., and A. Tversky. 1979. Prospect Theory: An Analysis of Decision under Risk. Econometrica. 47 263-292.

Keynes, M. 1936. The General Theory of Employment, Interest, and Money. London Macmillan.

Knight, F. H. 1921. Risk, Uncertainty, and Profit. Boston, MA; Hart, Schaffner \& Marx; Houghton Mifflin Co. 1st Edition.

Kraft, H., and M. Steffensen. 2013. A Dynamic Programming Approach to Constrained Portfolios. European Journal of Operational Research. 229 453-461.

Liu, J., J. Pan, and T. Wang. 2005. An Equilibrium Model of Rare-Event Premia and Its Implication for Option Smirks. Review of Financial Studies. 18 131-164.

Liu, J. 2007. Portfolio Selection in Stochastic Environments. Review of Financial Studies. $201-39$.

Maenhout, P. J. 2004. Robust Portfolio Rules and Asset Pricing. Review of Financial Studies. 17 951-983.

Marston, C. L., and B. M. Craven. 1998. A Survey of Corporate Perceptions on ShortTermism among Analysts and Fund Managers. European Journal of Finance. 4 233-256.

Merton, R. C. 1969. Lifetime Portfolio Selection under Uncertainty: The Continuous-Time Case. Review of Economics and Statistics. 51 247-257.

Merton, R. C. 1971. Optimal Consumption and Portfolio Rules in a Continuous-Time Model. Journal of Economic Theory. 3 373-413.

Tversky, A., and D. kahneman. 1992. Advances in Prospect Theory: Cumulative Representation of Uncertainty. Journal of Risk and Uncertainty. 5 297-323.

Uppal, R., and T. Wang. 2003. Model Misspecification and Underdiversification. Journal of 
Finance. 58 2465-2486.

Wachter, J. A., and M. Yogo. 2010. Why Do Household Portfolio Shares Rise in Wealth? Review of Financial Studies. 23 3929-3965. 


\begin{tabular}{ccccccc}
\hline \hline \multirow{8}{*}{$\gamma$} & \multicolumn{6}{c}{ the level of fund managers' ambiguity aversion $\theta$} \\
\cline { 2 - 7 } & 0 & 0.5 & 1 & 3 & 5 & 10 \\
\hline 1.5 & $131.3 \%$ & $98.5 \%$ & $78.8 \%$ & $43.8 \%$ & $30.3 \%$ & $17.1 \%$ \\
2 & $98.5 \%$ & $78.8 \%$ & $65.7 \%$ & $39.4 \%$ & $28.1 \%$ & $16.4 \%$ \\
5 & $39.4 \%$ & $35.8 \%$ & $32.8 \%$ & $24.6 \%$ & $19.7 \%$ & $13.1 \%$ \\
10 & $19.7 \%$ & $18.8 \%$ & $17.9 \%$ & $15.2 \%$ & $13.1 \%$ & $9.8 \%$ \\
\hline \hline \multicolumn{7}{c}{ (a) portfolio share } \\
\hline \hline \multicolumn{7}{c}{$\gamma$} \\
\cline { 2 - 7 } & the level of fund managers' ambiguity & aversion $\theta$ \\
\hline 1.5 & $7.5 \%$ & $5.6 \%$ & $4.5 \%$ & $2.5 \%$ & $1.7 \%$ & $1 \%$ \\
2 & $7.5 \%$ & $6.0 \%$ & $5.0 \%$ & $3.0 \%$ & $2.1 \%$ & $1.3 \%$ \\
5 & $7.5 \%$ & $6.8 \%$ & $6.3 \%$ & $4.7 \%$ & $3.8 \%$ & $2.5 \%$ \\
10 & $7.5 \%$ & $7.2 \%$ & $6.8 \%$ & $5.8 \%$ & $5.0 \%$ & $3.8 \%$ \\
\hline \hline
\end{tabular}

(b) equity premium

Table 1: The sensitivity of portfolio share and equity premium to changes in risk aversion $\gamma$ and ambiguity aversion $\theta$. Parameter values are set as follows: $r=0.0371$, $\mu=0.1123, \sigma=0.1954, T=1, \alpha=0.01, \underline{W}=0.9$, and $x=1$.

\begin{tabular}{c|c|c}
\hline \hline Parameters & Symbol & Value \\
\hline Risk-free interest rate & $r$ & $3.71 \%$ \\
Expected rate of stock return & $\mu$ & $11.23 \%$ \\
Stock volatility & $\sigma$ & $19.54 \%$ \\
Terminal time for a fund manager & $T$ & 1 \\
The probability of allowing the shortfall from VaR constraint & $\alpha$ & $1 \%$ \\
The floor of wealth & $\underline{W}$ & 0.9 \\
Initial value for underlying asset $X$ & $x$ & 1 \\
Relative risk aversion & $\gamma$ & 2 \\
Ambiguity aversion & $\theta$ & 3 \\
\hline \hline
\end{tabular}

Table 2: Summary of parameters. 


\begin{tabular}{ccccccc}
\hline \hline & \multicolumn{6}{c}{ the level of fund managers' ambiguity aversion $\theta$} \\
\cline { 2 - 7 } & 0 & 0.5 & 1 & 3 & 5 & 10 \\
\hline 1.5 & 0.6102 & 0.6883 & 0.7428 & 0.8568 & 0.9074 & 0.9611 \\
2 & 0.7012 & 0.7517 & 0.7893 & 0.8754 & 0.9174 & 0.9647 \\
5 & 0.8911 & 0.9015 & 0.9106 & 0.9376 & 0.9553 & 0.9806 \\
10 & 0.9624 & 0.9652 & 0.9679 & 0.9768 & 0.9838 & 0.9959 \\
\hline \hline
\end{tabular}

Table 3: The sensitivity of tolerance $k_{\alpha}$ for bearing losses to changes in risk aversion $\gamma$ and ambiguity aversion $\theta$. Parameter values are set as follows: $r=0.0371, \mu=0.1123$, $\sigma=0.1954, T=1, \alpha=0.01, \underline{W}=0.9$, and $x=1$.

\begin{tabular}{c|ccccc}
\hline \hline$\mu \backslash \sigma$ & 0.1754 & 0.1854 & 0.1954 & 0.2054 & 0.2154 \\
\hline 0.0923 & 0.9018 & 0.9084 & 0.9143 & 0.9198 & 0.9248 \\
0.1023 & 0.8802 & 0.8877 & 0.8945 & 0.9007 & 0.9064 \\
0.1123 & 0.8595 & 0.8678 & 0.8754 & 0.8823 & 0.8887 \\
0.1223 & 0.8397 & 0.8487 & 0.8570 & 0.8645 & 0.8715 \\
0.1323 & 0.8206 & 0.8303 & 0.8392 & 0.8473 & 0.8549 \\
\hline \hline
\end{tabular}

Table 4: The sensitivity of tolerance $k_{\alpha}$ for bearing losses to changes in expected rate $\mu$ of stock return and stock volatility $\sigma$. Parameter values are set as follows: $r=0.0371, \gamma=2, \theta=3, T=1, \alpha=0.01, \underline{W}=0.9$, and $x=1$.

\begin{tabular}{ccccccc}
\hline \hline \multirow{2}{*}{$\gamma$} & \multicolumn{6}{c}{ the level of fund managers' ambiguity aversion $\theta$} \\
\cline { 2 - 7 } & 0 & 0.5 & 1 & 3 & 5 & 10 \\
\hline 1.5 & $32.8 \%$ & $25.5 \%$ & $20.6 \%$ & $5.9 \%$ & $2.0 \%$ & $1.0 \%$ \\
2 & $30.6 \%$ & $23.8 \%$ & $17.8 \%$ & $4.7 \%$ & $1.8 \%$ & $1.0 \%$ \\
5 & $7.1 \%$ & $5.3 \%$ & $4.0 \%$ & $2.1 \%$ & $1.7 \%$ & $1.1 \%$ \\
7 & $3.5 \%$ & $3.0 \%$ & $2.7 \%$ & $1.9 \%$ & $1.6 \%$ & $1.1 \%$ \\
10 & $2.7 \%$ & $2.5 \%$ & $2.3 \%$ & $1.9 \%$ & $1.5 \%$ & $1.0 \%$ \\
\hline \hline
\end{tabular}

Table 5: The sensitivity of expected losses $L(\cdot)$ to changes in risk aversion $\gamma$ and ambiguity aversion $\theta$. Parameter values are set as follows: $r=0.0371, \mu=0.1123$, $\sigma=0.1954, T=1, \alpha=0.01, \underline{W}=0.9, x=1$, and $\xi=1$. 


\begin{tabular}{c|ccccc}
\hline \hline$\mu \backslash \sigma$ & 0.1754 & 0.1854 & 0.1954 & 0.2054 & 0.2154 \\
\hline 0.0923 & $2.6 \%$ & $2.2 \%$ & $1.9 \%$ & $1.7 \%$ & $1.5 \%$ \\
0.1023 & $4.2 \%$ & $3.6 \%$ & $3.0 \%$ & $2.6 \%$ & $2.3 \%$ \\
0.1123 & $6.5 \%$ & $5.5 \%$ & $4.7 \%$ & $4.0 \%$ & $3.5 \%$ \\
0.1223 & $9.2 \%$ & $7.9 \%$ & $6.8 \%$ & $5.9 \%$ & $5.1 \%$ \\
0.1323 & $12.3 \%$ & $10.7 \%$ & $9.3 \%$ & $8.1 \%$ & $7.1 \%$ \\
\hline \hline
\end{tabular}

Table 6: The sensitivity of expected losses $L(\cdot)$ to changes in expected rate $\mu$ of stock return and stock volatility $\sigma$. Parameter values are set as follows: $r=0.0371$, $\gamma=2, \theta=3, T=1, \alpha=0.01, \underline{W}=0.9, x=1$, and $\xi=1$.

\begin{tabular}{ccccccc}
\hline \hline \multirow{2}{*}{$\gamma$} & \multicolumn{6}{c}{ the level of fund managers' ambiguity aversion $\theta$} \\
\cline { 2 - 7 } & 0 & 0.5 & 1 & 3 & 5 & 10 \\
\hline 1.5 & $19.5 \%$ & $11.8 \%$ & $8.2 \%$ & $3.5 \%$ & $2.2 \%$ & $1.1 \%$ \\
2 & $15.2 \%$ & $10.1 \%$ & $7.4 \%$ & $3.4 \%$ & $2.2 \%$ & $1.1 \%$ \\
5 & $6.4 \%$ & $5.4 \%$ & $4.6 \%$ & $2.8 \%$ & $1.9 \%$ & $1.1 \%$ \\
7 & $4.6 \%$ & $4.1 \%$ & $3.6 \%$ & $2.4 \%$ & $1.8 \%$ & $1.0 \%$ \\
10 & $3.3 \%$ & $3.0 \%$ & $2.7 \%$ & $2.0 \%$ & $1.6 \%$ & $1.0 \%$ \\
\hline \hline
\end{tabular}

Table 7: The sensitivity of expected losses $L^{E S(\cdot)}$ to changes in risk aversion $\gamma$ and ambiguity aversion $\theta$. Parameter values are set as follows: $r=0.0371, \mu=0.1123$, $\sigma=0.1954, T=1, \epsilon=0.01, \underline{W}=0.9, x=1$, and $\xi=1$. 


\begin{tabular}{c|ccccc}
\hline \hline$\mu \backslash \sigma$ & 0.1754 & 0.1854 & 0.1954 & 0.2054 & 0.2154 \\
\hline 0.0923 & $2.6 \%$ & $2.4 \%$ & $2.3 \%$ & $2.1 \%$ & $2.0 \%$ \\
0.1023 & $3.3 \%$ & $3.0 \%$ & $2.8 \%$ & $2.6 \%$ & $2.5 \%$ \\
0.1123 & $4.0 \%$ & $3.7 \%$ & $3.4 \%$ & $3.2 \%$ & $3.0 \%$ \\
0.1223 & $4.8 \%$ & $4.4 \%$ & $4.1 \%$ & $3.8 \%$ & $3.6 \%$ \\
0.1323 & $5.7 \%$ & $5.3 \%$ & $4.9 \%$ & $4.5 \%$ & $4.2 \%$ \\
\hline \hline \multicolumn{7}{|c}{ (a) $r=0.0371$} \\
\hline \hline$r \backslash \sigma$ & 0.1754 & 0.1854 & 0.1954 & 0.2054 & 0.2154 \\
\hline 0.0171 & $5.8 \%$ & $5.4 \%$ & $5.0 \%$ & $4.6 \%$ & $4.3 \%$ \\
0.0271 & $4.9 \%$ & $4.5 \%$ & $4.2 \%$ & $3.9 \%$ & $3.6 \%$ \\
0.0371 & $4.0 \%$ & $3.7 \%$ & $3.4 \%$ & $3.2 \%$ & $3.0 \%$ \\
0.0471 & $3.2 \%$ & $3.0 \%$ & $2.8 \%$ & $2.6 \%$ & $2.5 \%$ \\
0.0571 & $2.6 \%$ & $2.4 \%$ & $2.2 \%$ & $2.1 \%$ & $2.0 \%$ \\
\hline \hline
\end{tabular}

Table 8: The sensitivity of expected losses $L^{E S}(\cdot)$ to changes in expected rate $\mu$ of stock return, risk-free interest rate $r$, and stock volatility $\sigma$. Parameter values are set as follows: $\gamma=2, \theta=3, T=1, \epsilon=0.01, \underline{W}=0.9, x=1$, and $\xi=1$. 


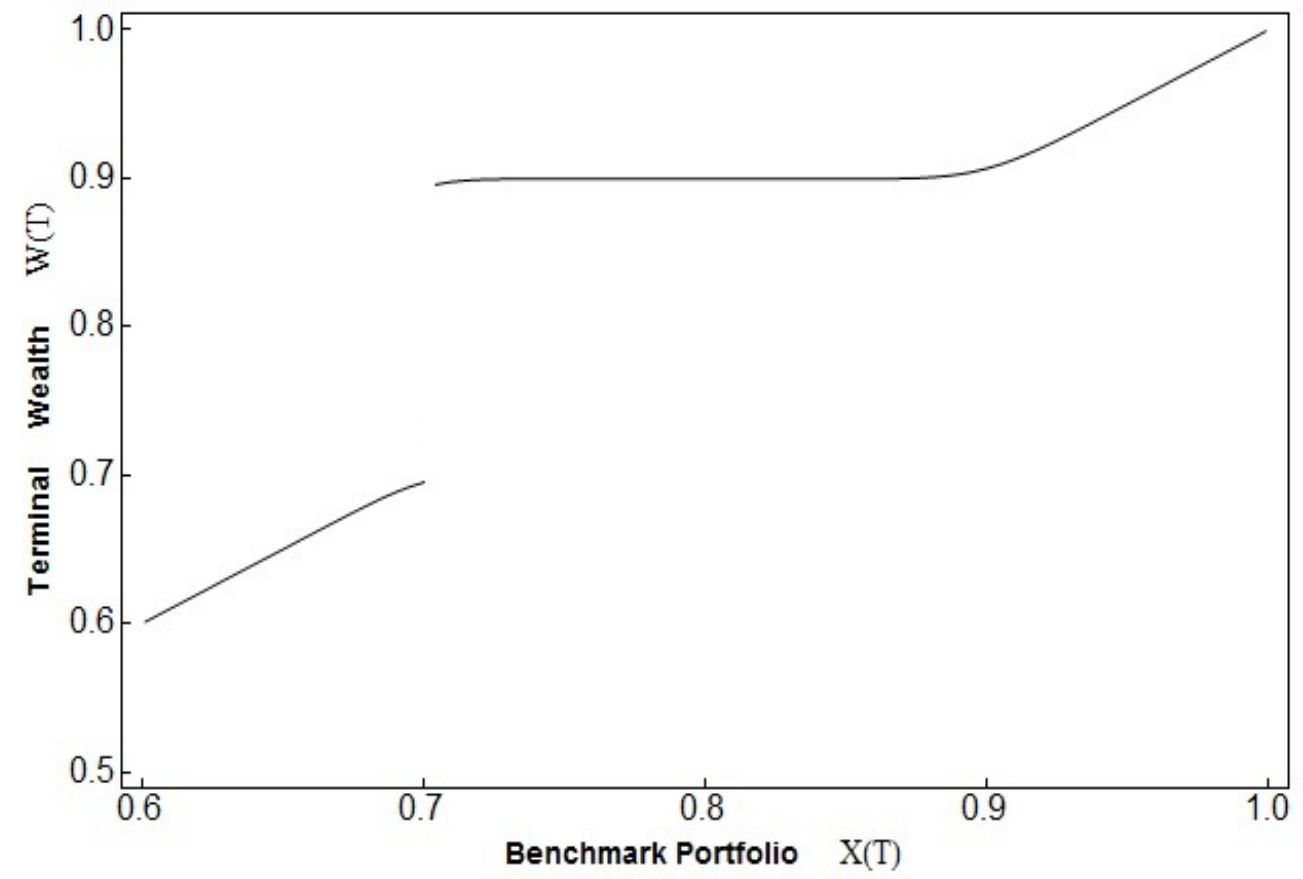

(a) $\theta=0$

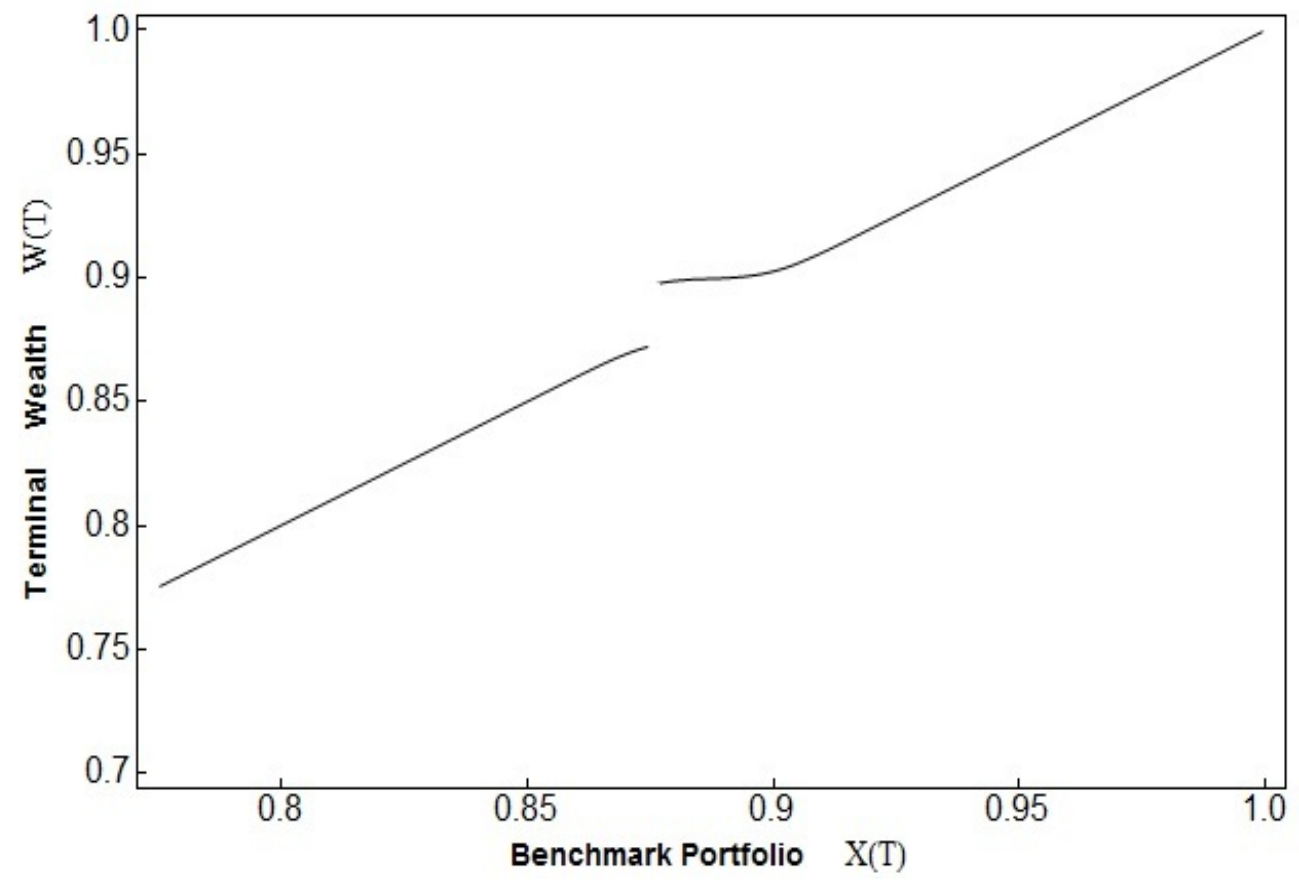

(b) $\theta=3$

Figure 1: Terminal wealth management $W(T)$. Parameter values are set as follows: $r=0.0371, \mu=0.1123, \sigma=0.1954, T=1, \alpha=0.01, \underline{W}=0.9, x=1$, and $\gamma=2$. 


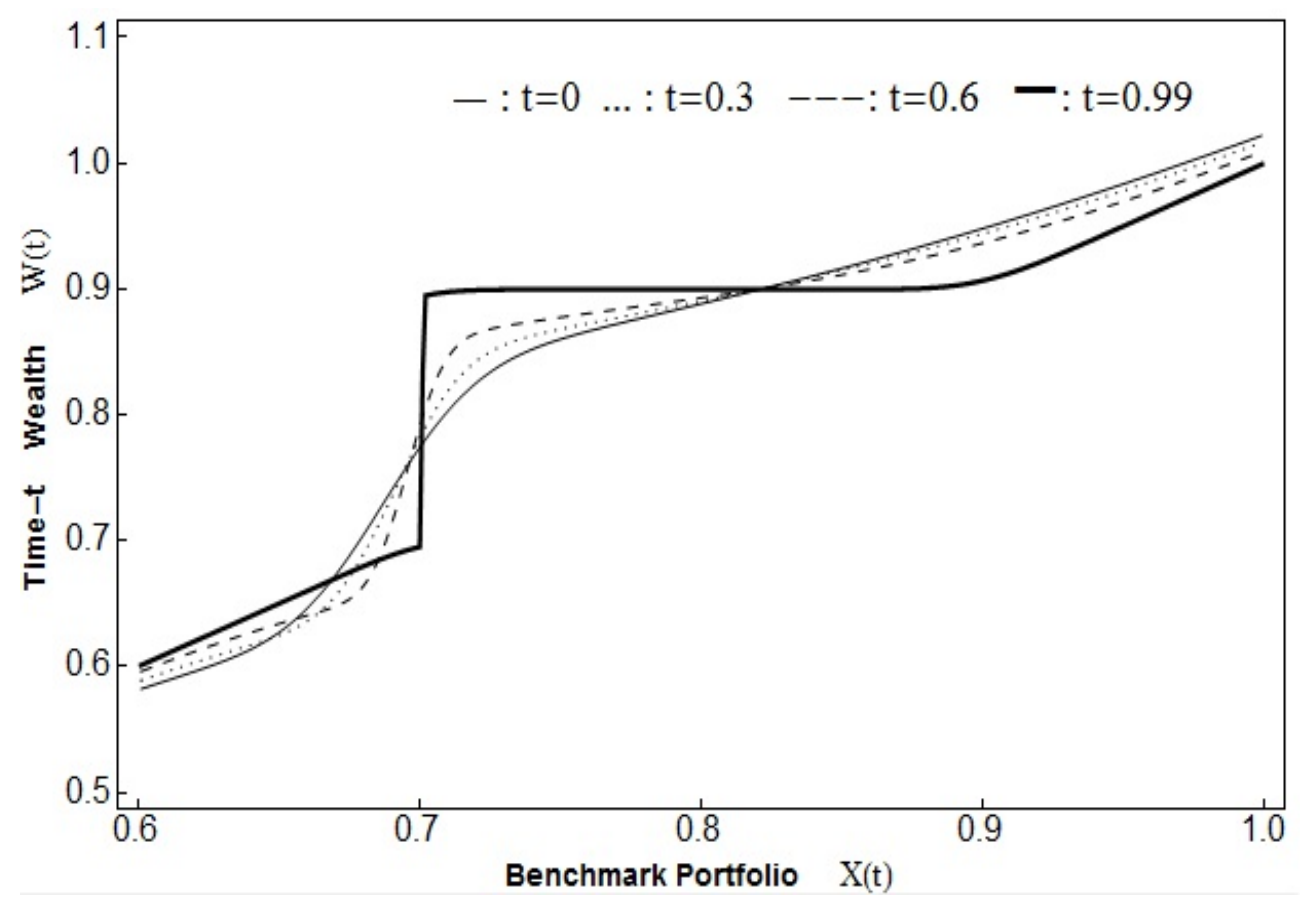

(a) $\theta=0$

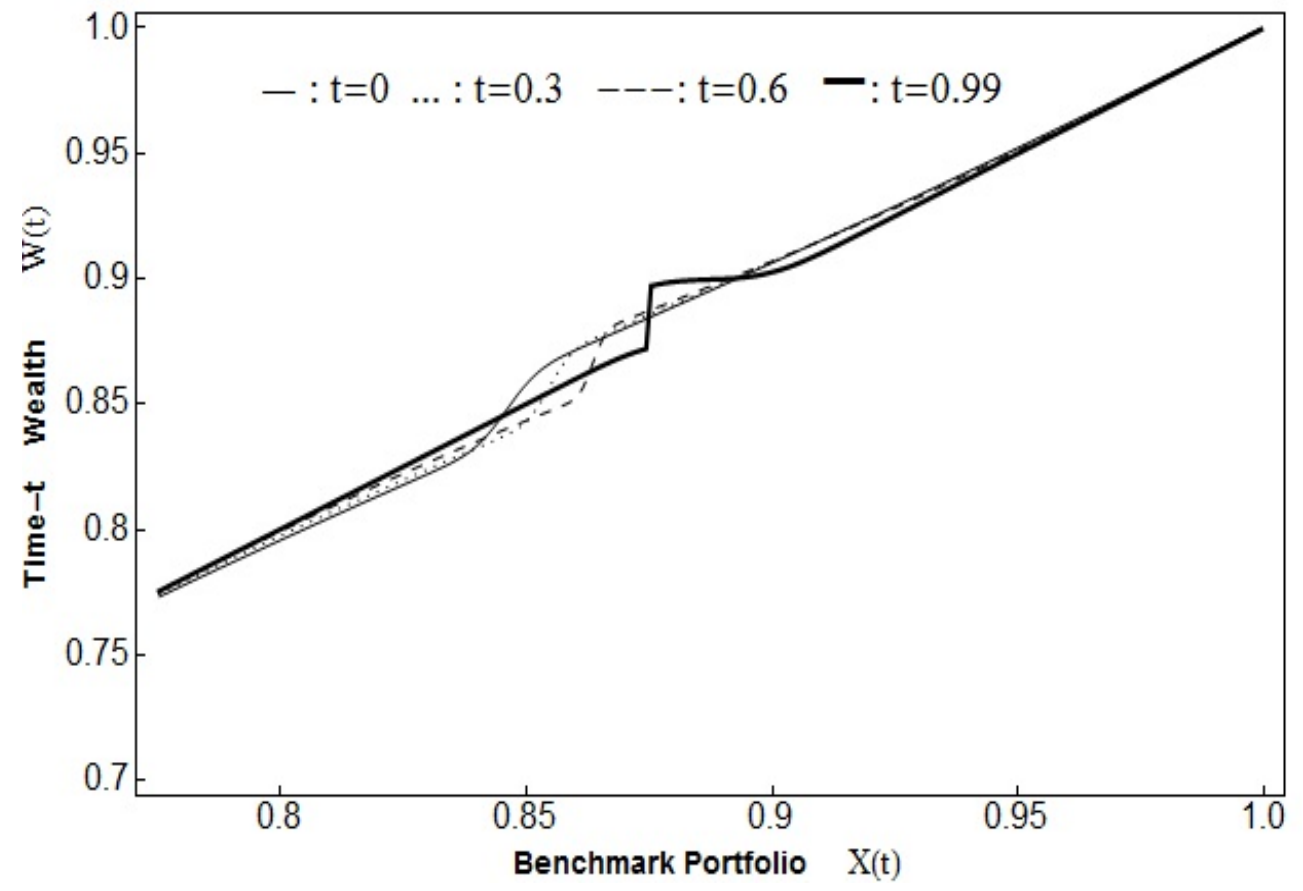

(b) $\theta=3$

Figure 2: Time- $t$ wealth management $W(t)$. Parameter values are set as follows: $r=$ 0.0371, $\mu=0.1123, \sigma=0.1954, T=1, \alpha=0.01, \underline{W}=0.9, x=1$, and $\gamma=2$. 


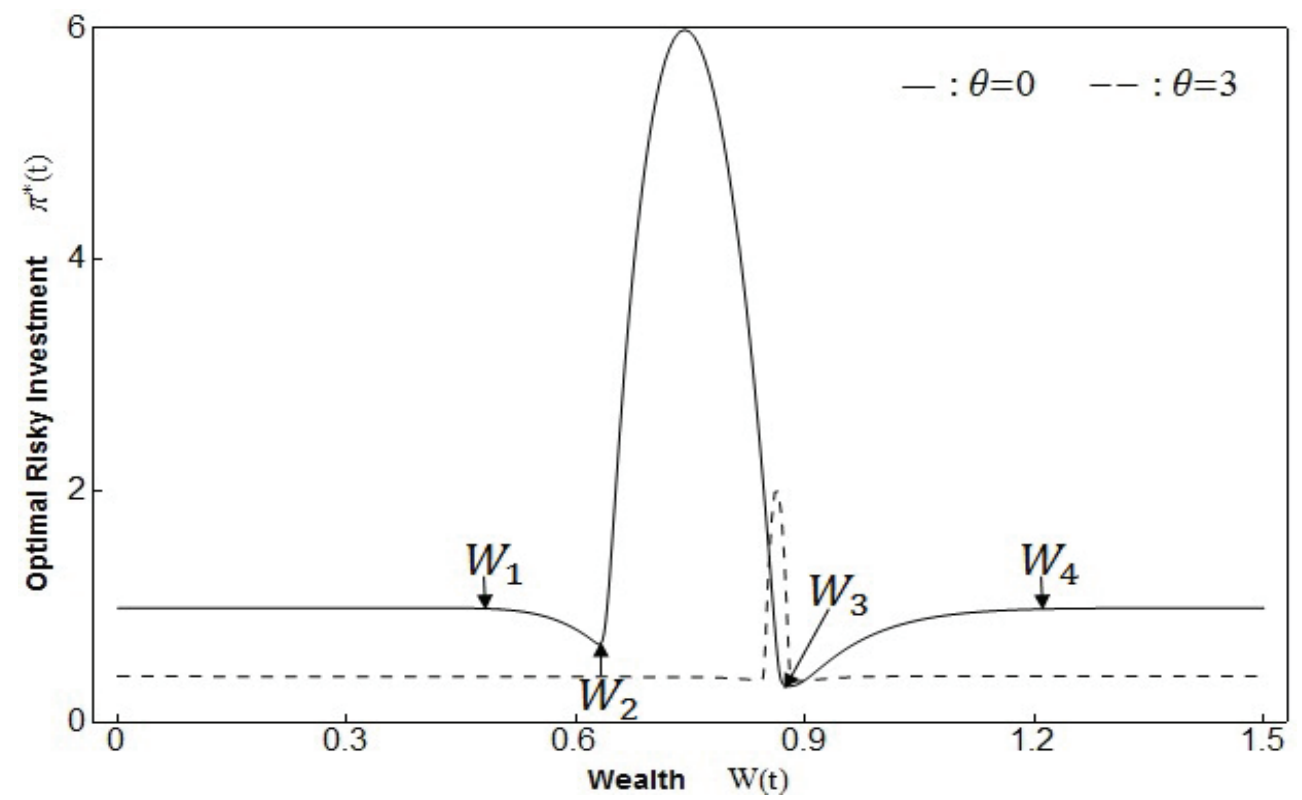

Figure 3: Optimal risky investment $\pi^{*}(t)$. Parameter values are set as follows: $r=0.0371$, $\mu=0.1123, \sigma=0.1954, t=0.5, T=1, \alpha=0.01, \underline{W}=0.9, x=1$, and $\gamma=2$.

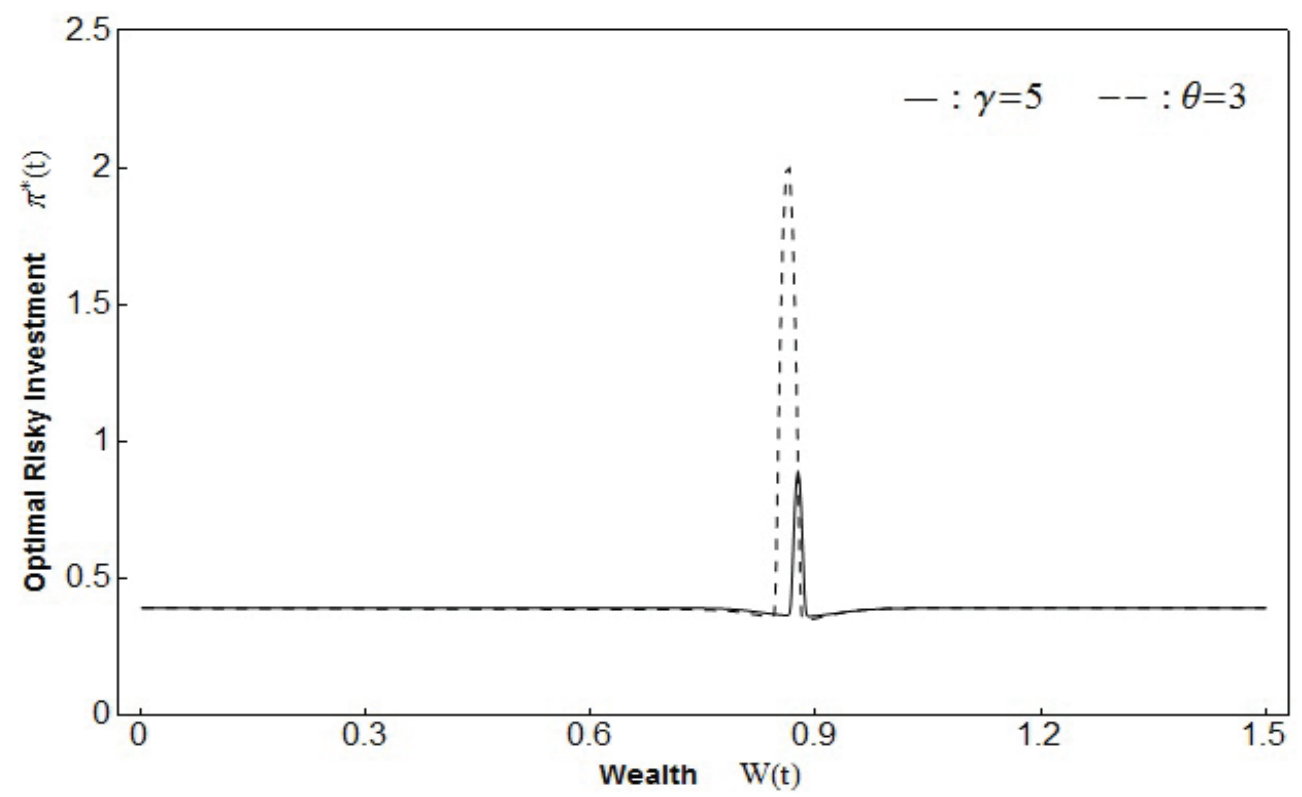

Figure 4: Optimal risky investment $\pi^{*}(t)$. Parameter values are set as follows: $r=0.0371$, $\mu=0.1123, \sigma=0.1954, t=0.5, T=1, \alpha=0.01, \underline{W}=0.9$, and $x=1$. In the figure, $\gamma=5$ and $\theta=3$ represent $(\gamma, \theta)=(5,0)$ and $(\gamma, \theta)=(2,3)$, respectively. We assume that the sum $\gamma+\theta$ is fixed to 5 . 

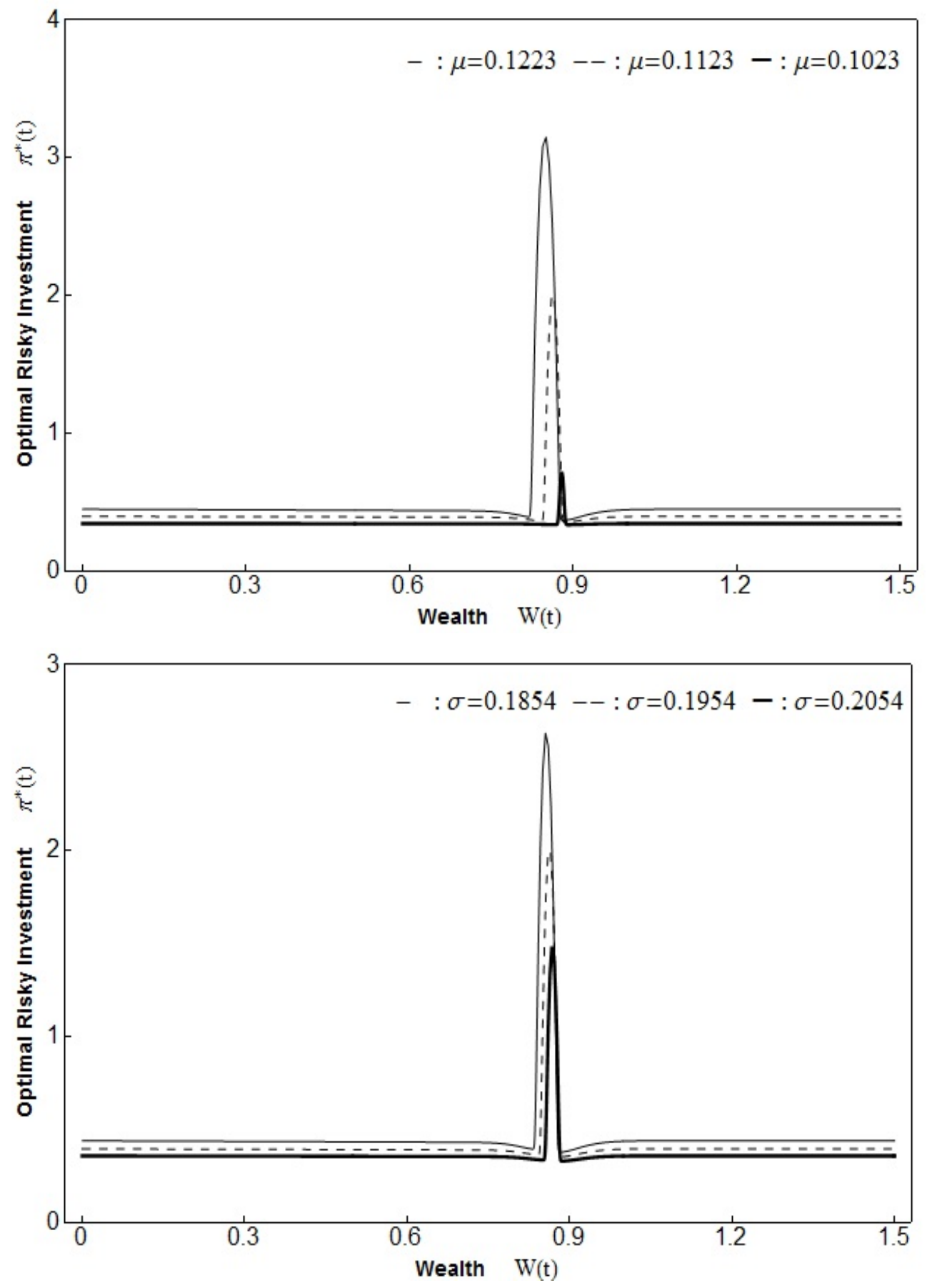

Figure 5: Optimal risky investment $\pi^{*}(t)$ with respect to changes in expected rate $\mu$ of stock return and stock volatility $\sigma$. Parameter values are set as follows: $r=0.0371$, $\gamma=2, \theta=3, \sigma=0.1954, t=0.5, T=1, \alpha=0.01, \underline{W}=0.9$, and $x=1$. 